\title{
Biodegradable PEG-Dendritic Block Copolymers: Synthesis and Biofunctionality Assessment as Vectors of siRNA
}

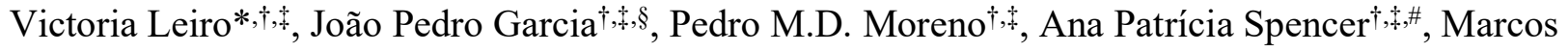

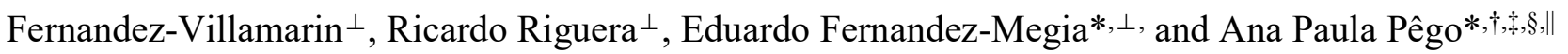 \\ $\dagger$ i3S - Instituto de Investigação e Inovação em Saúde and †INEB - Instituto de Engenharia Biomédica, \\ Universidade do Porto, Rua Alfredo Allen, 208, 4200-135 Porto, Portugal; § Faculdade de Engenharia \\ da Universidade do Porto (FEUP), and || Instituto de Ciências Biomédicas Abel Salazar (ICBAS) - \\ Universidade do Porto, Porto, Portugal.*e-mail: apego@ineb.up.pt; *e-mail: victoria.leiro@ineb.up.pt; \\ Tel: +351220408800 \\ \# Faculdade de Ciências e Tecnologia da Universidade Nova de Lisboa, Lisboa, Portugal \\ $\perp$ Department of Organic Chemistry and Center for Research in Biological Chemistry and Molecular \\ Materials (CIQUS), University of Santiago de Compostela, Jenaro de la Fuente s/n, 15782 Santiago de \\ Compostela, Spain; *e-mail: ef.megia@usc.es; Tel: +34 8818157277
}

KEYWORDS Dendrimers, Degradability, Esters, Gene Therapy, siRNA

\footnotetext{
ABSTRACT: One important drawback of the most currently used dendrimers for biomedical applications is their high stability under physiological conditions that can result in cytotoxicity or complications induced by the accumulation of non-degradable synthetic materials in the organism. Particularly in the gene therapy field, vector stability can further hinder the intracellular release of the nucleic acid from the dendriplex, consequently leading to low transfection efficiencies. Therefore, biodegradable cationic dendritic structures have been eagerly awaited. However, the development of these dendritic nanocarriers is challenging because of the undesired and/or premature degradation observed during their synthesis and/or application. Here, we report new hybrid-biodegradable, biocompatible, non-toxic, and watersoluble azide-terminated PEG-GATGE dendritic block copolymers, based on a gallic acid (GA) core and
} 
triethylene glycol (TG) butanoate arms, incorporating ester bonds (E) at the dendritic arms/shell. Their successful functionalization by "click" chemistry with unprotected alkynated amines allowed to complex and deliver siRNA. The hydrophobic character of the GATGE building unit confers to these hydrolyzable dendritic bionanomaterials a great ability to complex, protect and mediate the cellular internalization of siRNA. Moreover, the localization of the degradation points at the dendritic periphery, close to the complexed siRNA, was found important for the nucleic acid release from the nanoparticles, rendering a significant improvement of the transfection efficiency compared to their hydrolytically stable PEG-GATG copolymer counterparts. The present study puts forward these biodegradable PEG-dendritic block copolymers not only as suitable vectors for nucleic acids, but also opens new avenues for further developments exploring their use in theranostics.

\section{INTRODUCTION}

Dendritic nanostructures are considered promising vehicles for different bioactive molecules due to their globular, well defined and highly branched structure, low polydispersity and tunable size. ${ }^{1-5}$ The presence of chemical handles on the dendritic periphery further allows their functionalization with ligands in a specific and controlled manner to mimic the multivalency present in many biological systems. Particularly relevant is their capacity to complex and protect nucleic acids (NA) in compact nanostructures, coined "dendriplexes" (dendrimer-NA complexes), with application as non-viral vectors in gene therapy. ${ }^{6,7}$ Among these strategies to modulate gene expression, the down-regulation of protein production via RNA interference (RNAi) mediated by small interfering RNA (siRNA) has proven good therapeutic potential in clinical settings. ${ }^{8}$ However, despite its early success, the widespread use of RNAi therapeutics requires the development of clinically suitable, safe and effective delivery carriers with the ability to compact and protect naked siRNA.

Most of the siRNA non-viral carriers tested so far have been mainly based on cationic systems previously developed for the delivery of plasmid DNA (pDNA) such as, cell penetrating peptides, lipids, natural and synthetic polymers, and more recently, dendrimers. Cationic poly(amido amine) (PAMAM), poly(propylene imine) (PPI) and poly(L-lysine) (PLL) dendrimers, among others, have been reported as promising carriers of pDNA and siRNA. ${ }^{6,7,9,10}$ A common approach for masking the characteristic positive charge of the resulting nanoparticles/systems, and improving their biocompatibility and circulation time in the blood stream has been the tethering of poly(ethylene glycol) (PEG) chains. ${ }^{11-14}$ PEG-dendritic block copolymers are obtained when PEGylation is performed at the focal point of 
dendrimers. ${ }^{15}$ Several research groups, ${ }^{16-19}$ including ours with the GATG (Gallic Acid-Triethylene Glycol) family, ${ }^{20,} 21$ have reported on the use of PEG-dendritic block copolymers for the delivery of pDNA. The same strategy with siRNA has not been described until very recently with a fourth generation (G4) PEG-PAMAM. ${ }^{22}$

Despite the progress in the design and use of dendritic structures with improved features for NA delivery and other biomedical applications, most currently used dendritic families are very stable under physiological conditions, which might result in cytotoxicity induced by accumulation of non-degradable synthetic materials inside cells or in tissues. ${ }^{23-26}$ To overcome these hurdles, a number of teams are focusing on the design of biodegradable dendritic structures. ${ }^{27}$ Indeed, biodegradable materials that, under physiological conditions, degrade in time into smaller fragments (which can be excreted or eliminated through metabolic pathways), are expected to overcome the risk of complications associated with the long-term presence in tissues of non-degradable synthetic materials. ${ }^{28-32}$ Moreover, in gene therapy applications, biodegradable vectors are expected to facilitate the intracellular release of the NA from the dendriplex and so, ensure higher transfection efficiencies. ${ }^{33,34}$

Biodegradability in dendrimers can be achieved by inclusion of hydrolyzable bonds within the structure. ${ }^{27}$ Their topological location, along with the dendrimer size and hydrophobicity of the building blocks influence the degradation rate. Among the functionalities susceptible to degrade under physiological conditions, ester linkages are attractive due to a compromise between biodegradability trait and relative ease of synthetic manipulation. Even so, the preparation of ester-based nanocarriers is challenging because of undesired backbone degradation during synthesis, purification, and subsequent functionalization and processing steps. ${ }^{35,36}$ This explains the still reduced number of dendritic structures containing esters reported for specific functions in biomedicine. ${ }^{27}$ In the area of NA delivery these are restricted to very few examples with amine-terminated bis-HMPA [2,2-bis(hydroxymethyl)propanoic acid] dendrons for the encapsulation of DNA, largely described by Smith and coworkers. ${ }^{37-41}$ The challenge associated to combine in the same structure unprotected primary/secondary amine groups - needed to get the cationic charge to complex NAs - with hydrolyzable (and so, electrophilic) bonds adds extra struggle to the already difficult task of engineering biodegradable dendritic vectors.

Aiming at developing a biodegradable and PEGylated system for the delivery of siRNA, we have explored the PEG-GATG copolymer platform. ${ }^{42}$ GATG dendrimers involve a repeating unit carrying a gallic acid core and hydrophilic triethylene glycol arms linked by amide bonds. The functionalization of the peripheral azides in GATG with unprotected ligands (carbohydrates, anionic and cationic moieties, peptides, imaging agents) by the $\mathrm{Cu}(\mathrm{I})$-catalyzed azide-alkyne cycloaddition (CuAAC, "click" 
chemistry), ${ }^{43-45}$ has been exploited in the preparation of a variety of functional dendritic nanostructures for various biomedical applications. ${ }^{42,46}$
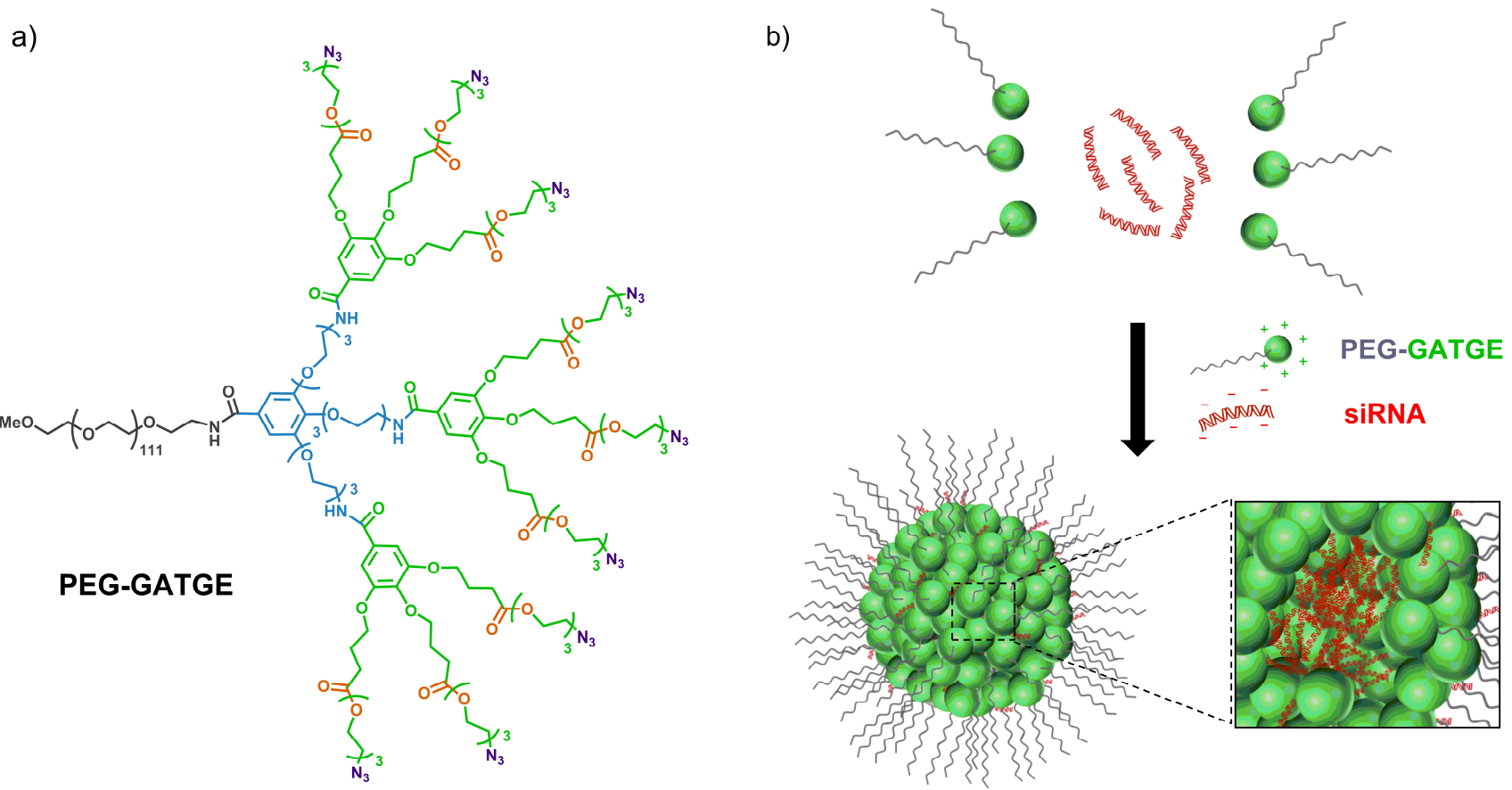

\section{DENDRIPLEX}

Figure 1. a) Structure of G2 hybrid-biodegradable PEG-GATGE block copolymer (PEG-b[G2]-N 3 ). b) Schematic representation of the preparation of siRNA dendriplexes by amine-terminated PEG-GATGE block copolymers.

Herein, we present a novel hybrid-biodegradable, biocompatible and non-toxic PEG-dendritic block copolymer of the GATG family, named PEG-GATGE (Gallic Acid-Triethylene Glycol Ester) (Figure 1a). The suitability of these copolymers as efficient vectors of siRNA is also reported, including a low cytotoxicity profile, as well as the abilities to protect siRNA from endonuclease degradation and transfect mammalian cells. Interestingly, the ester linkages in GATGE allow for a more effective siRNA release from the dendriplexes and hence, increased silencing compared to the homologous hydrolytically stable PEG-GATG copolymers. To the best of our knowledge, PEG-GATGE represents the first example of a biodegradable ester-based PEG-dendritic block copolymers developed for gene therapy applications.

\section{EXPERIMENTAL}




\subsection{Materials and instrumentation used for chemical characterization}

Dry $\mathrm{CH}_{2} \mathrm{Cl}_{2}$ was purchase from Prolabo. Dry DMF, Et 3 N, gallic acid, tert-butanol, oxalic acid, $\mathrm{NaHCO}_{3}$, $\mathrm{Na}_{2} \mathrm{SO}_{4}$, 4-bromobutanoic acid, N,N'-dicyclohexylcarbodiimide (DCC), dimethylaminopyridine (DMAP), $\mathrm{K}_{2} \mathrm{CO}_{3}, 18$-crown-6, $\mathrm{Pd} / \mathrm{C}$, hydroxybenzotriazole (HOBt), and sodium ascorbate were purchase from Sigma-Aldrich. $\mathrm{CuSO}_{4} \cdot 5 \mathrm{H}_{2} \mathrm{O}$ was obtained from Riedel-de-Haen and trifluoroacetic acid from Merck. Monomethyl ether PEG amino $\left(\mathrm{PEG}-\mathrm{NH}_{2} \cdot \mathrm{HCl}, \mathrm{Mn}=5,079 \mathrm{Da}, \mathrm{Mw}=5,113, \mathrm{Mw} / \mathrm{Mn}=1.007\right)$ was purchased from Jenkem Technology USA Inc. N1-(prop-2-yn-1-yl)propane-1,3-diamine·2 $\mathrm{HCl}$ and 4-ethynyl-benzenemethanamine $\cdot \mathrm{HCl}$ were purchase from Amatek Chemical Co Limited. All solvents were HPLC grade, purchased from Prolabo, Fluka and Sigma-Aldrich and used without further purification. Deuterated solvents were purchase from Cortecnet SAS. Column chromatography was performed with 230-400 mesh silica gel. Thin-layer chromatography (TLC) was done on silica 60/F-254 aluminum-backed plates (E. Merck). Ultrafiltration was performed on Amicon stirred cells with Ultracel ${ }^{\circledR}$ $1 \mathrm{kDa}$ membranes. Ultrafiltration membranes were purchase from Millipore Iberica, S.A. Nanopure water (18 $\mathrm{M} \Omega \cdot \mathrm{cm})$ was obtained from a Milli-Q water filtration system, Millipore Corp. Non-labeled siRNAmi/siRNA and siRNAmi/siRNA duplexes labeled at the 5' end of the sense strand were purchased from Integrated DNA Technologies. Nuclease free (NF) water was purchased from Qiagen. Luciferase assay system was purchased from Promega. Dulbecco's Modified Eagle's Medium (DMEM) and OptiMEM were purchased from Gibco. Fetal bovine serum (FBS) was purchased from Gibco. Cell culture plates were purchased from BD Biosciences. Hoechst 33342 was purchased from Life Technologies. U2OS cells stably expressing the fusion protein eGFP-Luciferase (U2OS/eGFPLuc cells) were kindly gifted by Prof. Edvard Smith (Karolinska Institute, Sweden).

2-[2-(2-azidoethoxy)ethoxy]ethanol （azidetriethylene glycol), 3,4,5-Tri-(2-(2-(2azidoethoxy)ethoxy)ethyl)benzoic acid (GATG building unit 7), and generations 1 and 2 of hydrolytically stable PEG-GATG dendritic block copolymers were prepared following protocols previously reported by us. ${ }^{47,48} \mathrm{~K}_{2} \mathrm{CO}_{3}$ was dried under reduced pressure at $65^{\circ} \mathrm{C}$.

NMR spectra were recorded with a Bruker Avance III $400 \mathrm{MHz}$ and a Bruker Avance III HD $600 \mathrm{MHz}$ spectrometers in $\mathrm{D}_{2} \mathrm{O}, \mathrm{CD}_{2} \mathrm{Cl}_{2}$, or $\mathrm{CDCl}_{3}$. Chemical shifts are reported in ppm ( $\delta$ units) and were referenced to the residual solvent signals $\left(\mathrm{CD}_{2} \mathrm{Cl}_{2}\right.$ and $\left.\mathrm{CDCl}_{3}\right)$ or the HOD signal $\left(\mathrm{D}_{2} \mathrm{O}\right)$. $J$ values are given in $\mathrm{Hz}$.

ESI-MS analysis were carried out with a LTQ Orbitrap XL mass spectrometer (Thermo Fischer Scientific, Bremen, Germany) controlled by LTQ Tune Plus 2.5.5 and Xcalibur 2.1.0. The capillary voltage of the electrospray ionization (ESI) was set to $3000 \mathrm{~V}$. The capillary temperature was $250^{\circ} \mathrm{C}$. The sheath gas 
flow rate (nitrogen) was set to 5 (arbitrary unit as provided by the software settings). The capillary voltage was $16 \mathrm{~V}$ and the tube lens voltage $80 \mathrm{~V}$.

IR spectra were recorded with a FTIR-RAMAN Perkin Elmer 2000 spectrometer (KBr) and a FT-IR Perkin Elmer Spectrum Two spectrometer equipped with a diamond crystal (ATR). For KBr technique, each pellet was prepared by blending $2 \mathrm{mg}$ of the PEG-dendritic block copolymer (vacuum dried $24 \mathrm{~h}$ at $45^{\circ} \mathrm{C}$ ) with $200 \mathrm{mg}$ of $\mathrm{KBr}$ (dried $24 \mathrm{~h}$ at $105^{\circ} \mathrm{C}$ ). After a 5-min purge of the sample chamber with $\mathrm{N}_{2}$, IR spectra were immediately recorded by accumulation of 200 interferograms at a $4 \mathrm{~cm}^{-1}$ spectral resolution over the range from 400 to $4000 \mathrm{~cm}^{-1}$ with background subtraction. For ATR technique, PEGdendritic block copolymers were used directly without further preparation. The IR spectra were recorded by accumulation of 20 interferograms at a $4 \mathrm{~cm}^{-1}$ spectral resolution over the range from 400 to $4000 \mathrm{~cm}^{-1}$ with background subtraction.

MALDI-TOF MS were carried out on a Bruker Autoflex III with NdYAG laser, operating in positive linear mode. Samples were dissolved in $\mathrm{MeOH}$ at a concentration $2 \times 10^{-4} \mathrm{M}$ and were mixed with the matrix (trans-2-[3-(4-tert-butylphenyl)-2-methyl-2-propenylidene]malononitrile, DCTB, $10 \mathrm{mg} / \mathrm{mL}$ in $\mathrm{CH}_{2} \mathrm{Cl}_{2}$ ) in a proportion matrix:sample $4: 1$. NaI was employed as cationizing agent.

\subsection{Synthesis and characterization}

tert-butyl gallate (2). $\mathrm{EDC} \cdot \mathrm{HCl}(1180 \mathrm{mg}, 6.17 \mathrm{mmol})$ was slowly added, in small portions, to a suspension of gallic acid $(1000 \mathrm{mg}, 5.88 \mathrm{mmol})$ in dry $\mathrm{tBuOH}(35 \mathrm{~mL})$. The reaction mixture was magnetically stirred at room temperature (RT) for $48 \mathrm{~h}$ under inert atmosphere (Ar). Then, $\mathrm{Et}_{2} \mathrm{O}$ (25-40 $\mathrm{mL}$ ) and oxalic acid $(970 \mathrm{mg}, 0.29 \mathrm{mmol})$ were added. The resulting mixture was filtered and the filtrate was washed with $0.3 \mathrm{M} \mathrm{NaHCO}_{3}$, dried $\left(\mathrm{Na}_{2} \mathrm{SO}_{4}\right)$ and concentrated to give $2(980 \mathrm{mg}, 74 \%)$ as a pale yellow solid. ${ }^{1} \mathrm{H}$ NMR (300 MHz, $\mathrm{CDCl}_{3}$ ) $\delta: 1.54$ (s, 9H), 5.22 (br s, 3H), 7.20 (s, 2H) (Figure S1). ${ }^{13} \mathrm{C}$ $\operatorname{NMR}\left(75 \mathrm{MHz}, \mathrm{CDCl}_{3}\right) \delta: 31.0,81.4,109.7,123.1,136.6,143.9,166.6$ (Figure S1). ${ }^{1} \mathrm{H}$ and ${ }^{13} \mathrm{C}$ NMR Spectra of 2 in Figure S1. ESI-MS Calculated for $\mathrm{C}_{11} \mathrm{H}_{13} \mathrm{O}_{5}:$ : 225.08412. Found [M-H]-: 225.07795.

2-[2-(2-azidoethoxy)ethoxy]ethyl 4-bromobutanoate (4). 2-[2-(2-azidoethoxy)ethoxy]ethanol (referred in the manuscript as "azidetriethylene glycol") (504 mg, $2.88 \mathrm{mmol}$ ), 4-bromobutanoic acid (720 mg, 4.31 mmol), DCC (890 mg, $4.31 \mathrm{mmol}$ ) and 4-dimethylaminopyridine (DMAP) (35 mg, $0.29 \mathrm{mmol}$ ) were dissolved in dry $\mathrm{CH}_{2} \mathrm{Cl}_{2}(5.7 \mathrm{~mL})$. The suspension was magnetically stirred for $12 \mathrm{~h}$ at $\mathrm{RT}$, after which $\mathrm{Et}_{3} \mathrm{~N}(1.0 \mathrm{~mL}, 7.19 \mathrm{mmol})$ was added and stirred for $1 \mathrm{~h}$. The suspension was evaporated and the resulting residue was resuspended in $\mathrm{Et}_{2} \mathrm{O}$ and filtered. The filtrate was evaporated and the resulting yellow oil was 
purified by column chromatography (hexane/ethyl acetate [2:1]) to yield 4 (906 $\mathrm{mg}, 97 \%$ ) as a pale-yellow oil. ${ }^{1} \mathrm{H}$ NMR (400 MHz, $\mathrm{CDCl}_{3}$ ) $\delta: 2.08$ (quint, $\left.J=6.8,2 \mathrm{H}\right), 2.44(\mathrm{t}, J=7.1,2 \mathrm{H}), 3.30(\mathrm{t}, J=4.6,2 \mathrm{H})$, $3.38(\mathrm{t}, J=6.5,2 \mathrm{H}), 3.57-3.64(\mathrm{~m}, 8 \mathrm{H}), 4.16(\mathrm{t}, J=4.7,2 \mathrm{H})$ (Figure $\mathrm{S} 2) .{ }^{13} \mathrm{C} \mathrm{NMR}\left(100 \mathrm{MHz}, \mathrm{CDCl}_{3}\right) \delta$ : 27.4, 32.1, 32.4, 50.3, 63.3, 68.8, 69.8, 70.3, 70.4, 172.1 (Figure S12). ESI-MS Calculated for $\mathrm{C}_{10} \mathrm{H}_{18} \mathrm{BrN}_{3} \mathrm{NaO}_{4}^{+}: 346.03784$. Found $[\mathrm{M}+\mathrm{Na}]^{+}: 346.03663$.

\section{3,4,5-tris(4-\{2-[2-(2-azidoethoxy)ethoxy]ethoxy\}-4-oxobutoxy)benzoic acid (5) (GATGE building}

unit). tert-butyl gallate 2 (97 mg, $0.43 \mathrm{mmol}$ ), dry $\mathrm{K}_{2} \mathrm{CO}_{3}(596 \mathrm{mg}, 4.31 \mathrm{mmol})$, and 18-crown-6 (11.4 $\mathrm{mg}, 0.04 \mathrm{mmol}$ ) were sequentially added to a solution of $4(559 \mathrm{mg}, 1.72 \mathrm{mmol})$ in dry DMF $(0.86 \mathrm{~mL})$ under Ar. Then, the reaction mixture was heated at $80^{\circ} \mathrm{C}$ for $12 \mathrm{~h}$ under magnetic stirring. After cooling down to RT, the solvent was evaporated and the resulting crude product was filtered to remove solid residues. The filtrate was concentrated and the resulting residue was purified by column chromatography (hexane/ethyl acetate [1:2]) to yield tris $\left\{2-\left[2-(2\right.\right.$-azidoethoxy)ethoxy]ethyl $\} \quad 4,4^{\prime}, 4 "$ - $\{[5$-(tertbutoxycarbonyl)benzene-1,2,3-triyl]tris(oxy) $\}$ tributanoate (336 mg, 82\%) as a pale yellow oil. ${ }^{1} \mathrm{H}$ NMR $\left(400 \mathrm{MHz}, \mathrm{CDCl}_{3}\right) \delta: 1.57(\mathrm{~s}, 9 \mathrm{H}), 1.98-2.16(\mathrm{dm}, 6 \mathrm{H}), 2.58(\mathrm{dt}, J=28.6, J=7.4,6 \mathrm{H}), 3.37(\mathrm{t}, J=5.0$, $6 \mathrm{H}), 3.63-3.71(\mathrm{~m}, 24 \mathrm{H}), 4.03(\mathrm{dt}, J=8.5, J=6.1,6 \mathrm{H}), 4.29-4.33(\mathrm{~m}, 6 \mathrm{H}), 7.18(\mathrm{~s}, 2 \mathrm{H})$ (Figure S3). ${ }^{13} \mathrm{C}$ NMR (100 MHz, $\left.\mathrm{CDCl}_{3}\right)$ \&: 24.6, 25.5, 28.1, 30.5, 30.6, 50.6, 63.4, 63.5, 67.9, 69.1, 69.2, 70.0, 70.6, 72.2, 81.1, 108.0, 127.0, 141.4, 152.3, 165.3, 173.0, 173.3 (Figure S3). EI-MS: Calculated for $\mathrm{C}_{41} \mathrm{H}_{65} \mathrm{~N}_{9} \mathrm{NaO}_{17}{ }^{+}: 978.43961 ;$ Found $[\mathrm{M}+\mathrm{Na}]^{+}: 978.43760$.

Tris $\{2-[2-(2-a z i d o e t h o x y) e t h o x y]$ ethyl $\}$

4,4',4"-\{[5-(tert-butoxycarbonyl)benzene-1,2,3triyl]tris(oxy) $\}$ tributanoate $(336 \mathrm{mg}, 0.35 \mathrm{mmol})$ was dissolved in a mixture of dried $\mathrm{CH}_{2} \mathrm{Cl}_{2} /$ trifluoroacetic acid $(1: 1)(3.5 \mathrm{~mL})$ and was stirred under $\mathrm{Ar}$ for $1.5 \mathrm{~h}$ and then concentrated to dryness to afford 3,4,5-tris(4-\{2-[2-(2-azidoethoxy)ethoxy]ethoxy $\}$-4-oxobutoxy)benzoic acid $\mathbf{5}$ as a pale yellow oil (316 mg, $100 \%) .{ }^{1} \mathrm{H}$ NMR (400 MHz, $\left.\mathrm{CDCl}_{3}\right) \delta: 2.09(\mathrm{dm}, 6 \mathrm{H}), 2.60(\mathrm{dt}, J=29.0, J=7.3$, $6 \mathrm{H}), 3.38(\mathrm{t}, J=5.0,6 \mathrm{H}), 3.65-3.72(\mathrm{~m}, 24 \mathrm{H}), 4.07(\mathrm{t}, J=6.1,6 \mathrm{H}), 4.23-4.27(\mathrm{~m}, 6 \mathrm{H}), 7.31(\mathrm{~s}, 2 \mathrm{H})$ (Figure S4). ${ }^{13} \mathrm{C} \mathrm{NMR}\left(100 \mathrm{MHz}, \mathrm{CDCl}_{3}\right) \delta: 24.4,25.4,30.4,30.5,50.5,63.3,63.5,67.8,69.0,69.0,69.9,70.4$, 70.5, 72.2, 108.4, 108.5, 124.2, 142.0, 142.3, 152.3, 170.3, 172.8, 173.2 (Figure S4). EI-MS: Calculated for $\mathrm{C}_{37} \mathrm{H}_{57} \mathrm{~N}_{9} \mathrm{NaO}_{17}+$ : 922.37646 ; Found $[\mathrm{M}+\mathrm{Na}]^{+}: 922.37809$.

PEG-b[G2]-N 3 (9). Pd/C (33 mg, 10\% w/w) was added to a solution of PEG-[G1]-N 3 (167 mg, 0.03 $\mathrm{mmol})$ in $\mathrm{MeOH}(10 \mathrm{~mL})$. The resulting mixture was vigorously stirred under $\mathrm{H}_{2}(1 \mathrm{~atm})$ for $5 \mathrm{~h}$. Then, the catalyst was removed by filtration and the filtrate was concentrated and dried. HOBt (18 mg, 0.13 
$\mathrm{mmol})$ and $\mathrm{EDC} \cdot \mathrm{HCl}(26 \mathrm{mg}, 0.13 \mathrm{mmol})$ were added to a solution of the above residue and $5(121 \mathrm{mg}$, $0.13 \mathrm{mmol})$ in dry $\mathrm{CH}_{2} \mathrm{Cl}_{2}(1 \mathrm{~mL})$. The resulting solution was stirred for $48 \mathrm{~h}$ at $\mathrm{RT}$ under inert atmosphere (Ar), and then it was concentrated and precipitated from $\mathrm{CH}_{2} \mathrm{Cl}_{2} / i \mathrm{PrOH}$ to give $\mathrm{PEG}-\mathrm{b}[\mathrm{G} 2]-\mathrm{N}_{3}$ as a white powder (208 mg, $86 \%$ ). FTIR (KBr): 3434, 2889, 2110, 1736, $1112 \mathrm{~cm}^{-1}$ (Figure S15). ${ }^{1} \mathrm{H}$ NMR (400 $\left.\mathrm{MHz}, \mathrm{CD}_{2} \mathrm{Cl}_{2}\right) \delta: 1.94-2.10(\mathrm{~m}, 18 \mathrm{H}), 2.48-2.60(\mathrm{~m}, 18 \mathrm{H}), 3.31-3.35(\mathrm{~m}, 21 \mathrm{H}), 3.39-3.78(\mathrm{~m}, \sim 554 \mathrm{H})$, 3.96-4.03 (m, 18H), 4.11-4.20 (m, $24 \mathrm{H}), 7.04-7.07(\mathrm{~m}, 8 \mathrm{H})$ (Figure S7). ${ }^{13} \mathrm{C}$ NMR $\left(100 \mathrm{MHz}, \mathrm{CD}_{2} \mathrm{Cl}_{2}\right) \delta$ : 24.1, 25.1, 29.9, 30.1, 39.5, 50.3, 50.3, 58.1, 62.9, 63.1, 67.5, 68.6, 68.7, 69.3, 69.4, 69.5, 70.0 , 71.4, 71.7, 105.3, 105.3, 129.4, 139.8, 151.9, 152.1, 166.3, 172.4, 172.7 (Figure S7). MALDI-TOF MS (DCTB + NaI, linear mode, $m / z): M p 8092.0\left([\mathrm{M}+\mathrm{Na}]^{+}\right), M \mathrm{n} 8045.5, M \mathrm{w}$ 8062.3. Calculated: $M \mathrm{p} 8222.4$ ([M $+\mathrm{Na}]^{+}$), Mn 8269.0 (Figure S14).

\section{General procedure for the multivalent functionalization of PEG-GATGE-N 3 and PEG-GATG-N 3 with alkynated amine ligands by $\mathrm{CuAAC}$}

PEG-GATG dendritic block copolymers (PEG-b[G2]-N 3 and PEG-[G2]-N 3 ) were dissolved in DMF/ $\mathrm{H}_{2} \mathrm{O}$ (1:1) to give a $0.1 \mathrm{M}$ final concentration of terminal azides. Then, alkynated ammonium salts $\mathbf{1 0}$ and $\mathbf{1 1}$ (200 mol \% per azide) and aqueous $0.1 \mathrm{M} \mathrm{CuSO}_{4} \cdot 5 \mathrm{H}_{2} \mathrm{O}(5 \mathrm{~mol} \%$ per azide) and $0.1 \mathrm{M}$ sodium ascorbate ( $25 \mathrm{~mol} \%$ per azide) were added. The resulting solution was stirred at RT for $24 \mathrm{~h}$, and the product was isolated by ultrafiltration (Ultracel ${ }^{\circledR} 1,000 \mathrm{MWCO}$ ) of the concentrated reaction mixture washing with 0.1 M EDTA (pH 6), $0.6 \mathrm{M} \mathrm{NaCl}$ and $\mathrm{H}_{2} \mathrm{O}$.

bD (12). From PEG-b[G2]-N $\mathrm{N}_{3}(92 \mathrm{mg}, 11.4 \mu \mathrm{mol}), 10$ (38 mg, $\left.0.21 \mathrm{mmol}\right), 0.1 \mathrm{M}$ sodium ascorbate (257 $\mu \mathrm{L})$, and $0.1 \mathrm{M} \mathrm{CuSO}_{4} \cdot 5 \mathrm{H}_{2} \mathrm{O}(51 \mu \mathrm{L})$ in DMF $(514 \mu \mathrm{L}) / \mathrm{H}_{2} \mathrm{O}(206 \mu \mathrm{L})$, and following the above general procedure, bD (111 mg, $100 \%)$ was obtained as a white foaming solid. ${ }^{1} \mathrm{H}$ NMR $\left(400 \mathrm{MHz}, \mathrm{D}_{2} \mathrm{O}\right) \delta$ : 1.98-2.07 (m, 18H), 2.14 (quint, $J=7.8,18 \mathrm{H}), 2.56-2.65(\mathrm{~m}, 18 \mathrm{H}), 3.14(\mathrm{t}, J=7.8, \sim 18 \mathrm{H}), 3.21(\mathrm{t}, J=$ 7.3, 18H), $3.42(\mathrm{~s}, 3 \mathrm{H}), 3.57-3.86(\mathrm{~m}, \sim 536 \mathrm{H}), 3.95-4.09(\mathrm{~m}, 42 \mathrm{H}), 4.23-4.25(\mathrm{~m}, \sim 18 \mathrm{H}), 4.40-4.41(\mathrm{~m}$, $\sim 18 \mathrm{H}), 4.64-4.67(\mathrm{~m}, \sim 18 \mathrm{H}), 7.08-7.11(\mathrm{~m}, \sim 8 \mathrm{H}), 8.21(\mathrm{~s}, 6 \mathrm{H}), 8.22(\mathrm{~s}, 3 \mathrm{H}) .{ }^{13} \mathrm{C}$ NMR $\left(100 \mathrm{MHz}, \mathrm{D}_{2} \mathrm{O}\right)$ $\delta: 24.8,25.0,25.8,31.3,31.4,37.6,40.5,40.7,42.5,45.0,51.0,59.0,64.7,64.8,68.8,69.3,69.6,69.8$, $69.8,70.0,70.3,70.5,71.9,73.5,106.3,127.3,130.1,130.2,139.3,140.1,140.2$, 140.5, 152.7, 152.9, 169.6, 176.2, 176.3. An intramolecular degradation up to $5 \%$ was determined for $\mathbf{1 2}$ by integration of the appropriate signals (k, 1, n, o, p and q) in the ${ }^{1} \mathrm{H}$ NMR spectrum (Figure S8 and Figure 3). 
bB (13). From PEG-b[G2]-N 3 (45 mg, $5.57 \mu \mathrm{mol}), 11$ (17 mg, $0.10 \mathrm{mmol}), 0.1 \mathrm{M}$ sodium ascorbate (124 $\mu \mathrm{L})$, and $0.1 \mathrm{M} \mathrm{CuSO}_{4} \cdot 5 \mathrm{H}_{2} \mathrm{O}(25 \mu \mathrm{L})$ in DMF $(249 \mu \mathrm{L}) / \mathrm{H}_{2} \mathrm{O}(100 \mu \mathrm{L})$, and following the above general procedure, bB (53 mg, $100 \%$ ) was obtained as a white foaming solid. ${ }^{1} \mathrm{H}$ NMR (400 MHz, $\left.\mathrm{D}_{2} \mathrm{O}\right) \delta: 1.73$ $1.88(\mathrm{~m}, 18 \mathrm{H}), 2.33-2.39(\mathrm{~m}, 18 \mathrm{H}), 3.42(\mathrm{~s}, 3 \mathrm{H}), 3.55-3.95(\mathrm{~m}, \sim 578 \mathrm{H}), 4.08-4.14(\mathrm{~m}, 36 \mathrm{H}), 4.52-4.55$ (m, 18H), 6.88-6.92 (m, 8H), 7.34-7.43 (m, 18H), 7.66-7.85 (m, 18H), 8.21-8.23 (m, 9H) (Figure S9). ${ }^{13} \mathrm{C}$ NMR (100 MHz, $\left.\mathrm{D}_{2} \mathrm{O}\right) \delta: 24.4,25.2,30.7,40.0,40.2,43.2,50.5,58.5,64.3,64.3,67.7,68.1,68.6,68.8$, 69.1, 69.4, 69.5, 70.0, 70.4, 71.4, 72.2, 72.5, 72.7, 105.9, 122.9, 126.3, 129.9, 130.6, 133.4, 139.7, 146.9, , 152.3, 152.3, 168.7, 175.4, 175.5.

hsD (14). From PEG-[G2]-N 3 (45 mg, $6.09 \mu \mathrm{mol}), 10$ (20 mg, $0.11 \mathrm{mmol}), 0.1$ M sodium ascorbate (132 $\mu \mathrm{L})$, and $0.1 \mathrm{M} \mathrm{CuSO}_{4} \cdot 5 \mathrm{H}_{2} \mathrm{O}(27 \mu \mathrm{L})$ in DMF $(264 \mu \mathrm{L}) / \mathrm{H}_{2} \mathrm{O}(105 \mu \mathrm{L})$, and following the above general procedure, hsD (52 mg, $94 \%$ ) was obtained as a white foaming solid. ${ }^{1} \mathrm{H}$ NMR (400 MHz, $\left.\mathrm{D}_{2} \mathrm{O}\right) \delta: 2.06$ $2.14(\mathrm{~m}, 18 \mathrm{H}), 3.13(\mathrm{t}, J=7.7,36 \mathrm{H}), 3.44(\mathrm{~s}, 3 \mathrm{H}), 3.56-3.94(\mathrm{~m}, \sim 536 \mathrm{H}), 3.97-4.01(\mathrm{~m}, 18 \mathrm{H}), 4.16-4.3$ (m, $24 \mathrm{H}), 4.28-4.33(\mathrm{~m}, 18 \mathrm{H}), 4.66(\mathrm{t}, J=4.8,18 \mathrm{H}), 7.14-7.17(\mathrm{~m}, 8 \mathrm{H}), 8.16-8.23(\mathrm{~m}, 9 \mathrm{H})$ (Figure S10). ${ }^{13} \mathrm{C}$ NMR $\left(100 \mathrm{MHz}, \mathrm{D}_{2} \mathrm{O}\right) \delta: 24.4,37.1,40.1,42.0,44.5,50.5,58.5,68.8,69.1,69.1,69.3,69.5,70.0$, $71.4,72.5,106.8,126.8,129.9,139.0,140.1,152.3,169.5$ (Figure S11).

hsB (15). From PEG-GATG-N 3 (G2) $(52.5 \mathrm{mg}, 7.11 \mu \mathrm{mol}), 11(21 \mathrm{mg}, 0.13 \mathrm{mmol}), 0.1 \mathrm{M}$ sodium ascorbate $(160 \mu \mathrm{L})$, and $0.1 \mathrm{M} \mathrm{CuSO}_{4} \cdot 5 \mathrm{H}_{2} \mathrm{O}(32 \mu \mathrm{L})$ in DMF $(320 \mu \mathrm{L}) / \mathrm{H}_{2} \mathrm{O}(128 \mu \mathrm{L})$, and following the above general procedure, PEG- [G2]-B (62 mg, $98 \%$ ) was obtained as a white foaming solid. ${ }^{1} \mathrm{H}$ NMR $\left(400 \mathrm{MHz}, \mathrm{D}_{2} \mathrm{O}\right) \delta: 3.43(\mathrm{~s}, 3 \mathrm{H}), 3.57-3.80(\mathrm{~m}, \sim 560 \mathrm{H}), 3.88-3.94(\mathrm{~m}, 18 \mathrm{H}), 4.02-4.07(\mathrm{~m}, 18 \mathrm{H}), 4.52-$ $4.57(\mathrm{~m}, 18 \mathrm{H}), 6.72-6.80(\mathrm{~m}, 8 \mathrm{H}), 7.22-7.33(\mathrm{~m}, 18 \mathrm{H}), 7.46-7.83(\mathrm{~m}, 18 \mathrm{H}), 8.16-8.17(\mathrm{~m}, 9 \mathrm{H})$ (Figure S12). ${ }^{13} \mathrm{C}$ NMR (100 MHz, $\left.\mathrm{D}_{2} \mathrm{O}\right) \delta: 39.9,40.1,43.1,50.5,58.5,68.5,68.6,69.0,69.0,69.4,69.5,69.7$, 69.9, 70.0, 70.2 , 70.4, 71.4, 72.2, 72.3, 72.4, 106.3, 106.2, 122.9, 126.0, 129.4, 129.7, 130.3, 133.1, 139.7, $146.8,151.5,151.7,151.8,168.6,168.7$ (Figure S13).

\subsection{Degradability studies}

Degradation of ammonium salt 6 and the dendritic copolymers bD (12) and bB (13) were studied simulating physiological $\mathrm{pH}$ conditions at $37^{\circ} \mathrm{C}$. Samples $(1 \mathrm{mg} / \mathrm{mL})$ were incubated at $37^{\circ} \mathrm{C}$ in phosphate 
buffered saline (PBS 3x, pD 7.4) and/or in acetate buffer saline (30 mM NaOAc $+420 \mathrm{mM} \mathrm{NaCl}, \mathrm{pD}$ 5.0). Buffers were prepared in deuterium oxide. Moreover, for the case of ammonium salt $\mathbf{6}$, buffers were supplemented with acetone-d6 $\left(\mathrm{D}_{2} \mathrm{O} /\right.$ acetone-d6, 85:15) with the aim of improving solubility and resolution of NMR spectra for integration purposes. Samples were analyzed by ${ }^{1} \mathrm{H}-\mathrm{NMR}$ at different time points.

\subsection{Dendriplex preparation}

Dendritic copolymer/siRNA complexes were prepared at N/P ratios (where $\mathrm{N}=$ number of primary amines in the conjugate; $\mathrm{P}=$ number of phosphate groups in the RNA backbone) ranging from 20 to 160 by adding siRNA $(20 \mu \mathrm{M})$ to different volumes of dendritic copolymer solution $(6 \mathrm{mg} / \mathrm{mL})$ in Nuclease-Free (NF) water (Qiagen). Then dendriplex solutions were vortexed for $10 \mathrm{sec}$ and allowed to incubate for $30 \mathrm{~min}$ at RT prior to experiments. For the experiments where biological activity is not assessed, a double stranded DNA of exact same sequence as anti-enhanced green fluorescence protein siRNA (anti-eGFP siRNA) was used for mimicking siRNA (siRNAmi) for its ease of synthesis and possibility to obtain in higher yields and purity.

siRNA sequence: sense 5'-GCUGACCCUGAAGUUCAUCUGCACC-3'.

\subsection{Polyacrylamide gel electrophoresis shift assay}

Polyacrylamide gels (with $4 \%$ stacking and 15\% resolving gel) were prepared in Tris/Borate/EDTA buffer (TBE buffer). Dendriplex solutions were prepared at different N/P ratios as previously described with the difference that siRNAmi (where the RNA nucleotides were substituted by DNA) was used instead of siRNA. The amount of dendriplex corresponding to 12 pmol of siRNAmi was mixed with $6 \mu \mathrm{L}$ of loading buffer and subjected to gel electrophoresis at $100 \mathrm{~V}$. Dendriplex/siRNAmi binding was shown by a lack of migration of the siRNAmi in the electrophoretic field (retention in the wells).

\subsection{SYBRGold ${ }^{\circledR}$ intercalation assay}

siRNAmi dendriplexes were prepared as previously described and then incubated in NF water (Qiagen)

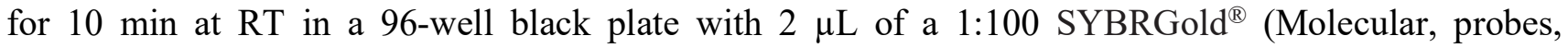
Invitrogen) solution (in TAE buffer) (final volume of $200 \mu \mathrm{L}$ ). After incubation, fluorescence was 
measured $\left(\lambda_{\mathrm{exc}}=485 \mathrm{~nm}, \lambda_{\mathrm{em}}=540 \mathrm{~nm}\right.$ ) using a micro-plate reader (SynergyMx, Biotek). Results are given as percentage of complexation, where $100 \%$ represents complete siRNA complexation. The presented data are expressed as mean $\pm \mathrm{SD}$ of three independent sample measurements.

\subsection{Size and zeta potential measurements}

Size, polydispersity index (PDI) and zeta potential (ZP) of dendriplexes were measured at $633 \mathrm{~nm}$ on a dynamic light scattering (DLS) instrument (Zetasizer Nano ZS, Malvern Instruments, UK) following the manufacturer instructions. Size and PDI were determined at RT with a detection angle of $173^{\circ}$. Zeta potential measurements were performed with a detection angle of $173^{\circ}$. For size and PDI measurements dendriplexes were prepared in a final volume of $80 \mu \mathrm{L}$ at different $\mathrm{N} / \mathrm{P}$ ratios and analyzed either undiluted or, in the case of stability studies, further diluted 2-fold in 1x PBS with 20\% (v/v) fetal bovine serum (FBS), in 1x PBS pH 7.4, and/or in $10 \mathrm{mM} \mathrm{NaOAc}+137 \mathrm{mM} \mathrm{NaCl} \mathrm{pH}$ 5.0. For ZP measurements, dendriplexes were prepared in a final volume of $250 \mu \mathrm{L}$ and diluted to $750 \mu \mathrm{L}$ in Milli Q water prior to the measurements. The Smoluchowski model was applied for zeta potential determination, and cumulant analysis was used for mean particle size determination. The presented data are expressed as the mean \pm SD of three independent sample measurements.

For analysis of heparin-induced dissociation of dendriplexes, these were prepared at N/P 160 after which an aliquot was diluted in 1x PBS containing different heparin concentrations (previously diluted in $1 \mathrm{x}$ PBS also). Dendriplexes and heparin were then incubated for $2 \mathrm{~h}$ at $37^{\circ} \mathrm{C}$. After incubation, dendriplexes (corresponding to 6 pmol siRNA) were loaded in 4-15\% (w/v) polyacrylamide-TBE gels and stained subsequently with SYBRGold ${ }^{\circledR}$.

\subsection{Transmission electron microscopy (TEM)}

Dendriplexes were prepared as previously described at N/P ratios of 80 and 160. Samples were mounted on a 200-mesh Ni grid with Formvar and carbon supporting film (not glow discharged) and stained with $2 \%$ uranyl acetate (UA) solution. Excess stain was removed with filter paper, and the grid was dried prior to imaging. Samples were imaged using a Jeol JEM 1400 operated at $80 \mathrm{kV}$. Images were processed using ImageJ $1.49 \mathrm{~K}$ software (NIH, USA).

\subsection{Dendriplexes degradation studies}

Biodegradable dendriplexes were prepared as previously described at N/P ratio of 160 and further diluted 2-fold in acetate buffer solution (60 mM NaOAc, pH 5.0) and in Sørensen's phosphate buffer solution 
(60 $\left.\mathrm{mM} \mathrm{NaH}_{2} \mathrm{PO}_{4}, \mathrm{pH} 7.4\right)$ for 1, 24 and $48 \mathrm{~h}$. After that, dendriplexes were incubated with heparin (at a final heparin concentration of $0.010 \mathrm{mg} / \mathrm{mL}$ and $0.025 \mathrm{mg} / \mathrm{mL}$ for $\mathrm{bD}$ and $\mathrm{bB}$ dendriplexes, respectively) for $2 \mathrm{~h}$ at $37^{\circ} \mathrm{C}$. After incubation, dendriplexes (corresponding to 3 pmol siRNA) were loaded in 4-15\% polyacrylamide-TBE gels and stained subsequently with SYBRGold ${ }^{\circledR}$.

\subsection{Nuclease protection assay}

Dendriplexes with a N/P ratio of 160 were prepared as previously described and incubated with $0.1 \mathrm{U}$ DNase I per $0.2 \mu \mathrm{g}$ of siRNAmi (annealed sense and antisense DNA strands mimicking siRNA) for 5, 15, 30 and 60 minutes at RT. For DNase inactivation samples were treated with ethylenediamine tetraacetic acid (EDTA; $0.05 \mathrm{M}$ final concentration), heated up to $65^{\circ} \mathrm{C}$ for $10 \mathrm{~min}$ and further stabilized for $30 \mathrm{~min}$ at RT. Mixtures were treated with sodium dodecyl sulfate (SDS) to a final concentration of $0.1 \%$ and incubated for another $30 \mathrm{~min}$. Finally, 1 pmol of siRNAmi was diluted in NF water (final volume $10 \mu \mathrm{L}$ ), mixed with LB and further loaded into a polyacrylamide gel $(10 \% \mathrm{w} / \mathrm{v})$. Naked siRNAmi and untreated dendriplexes were used as controls. Free wells were loaded with equivalent concentrations of salts, SDS and EDTA to allow a uniform band migration. The optimal DNase I concentration was previously determined by gel electrophoresis using naked siRNAmi.

\subsection{Cell culture}

The osteosarcoma cell line U2OS were cultured in DMEM media supplemented with $10 \%(\mathrm{v} / \mathrm{v})$ heat inactivated FBS $\left(56^{\circ} \mathrm{C}, 30 \mathrm{~min}\right.$ ) and $40 \mu \mathrm{g} / \mathrm{mL}$ gentamicin (Gibco, Life Technologies) at $37^{\circ} \mathrm{C}, 5 \% \mathrm{CO}_{2}$, in a cell incubator.

\subsection{Cytotoxicity studies}

Cell viability was evaluated as a function of the dendritic copolymer/dendriplex type and concentration. U2OS/eGFPLuc cells were seeded in 96-well plates at a density of $3.75 \times 10^{4} \mathrm{cells} / \mathrm{cm}^{2}$. At the time of transfection, the medium was replaced with non-supplemented DMEM.

$24 \mathrm{~h}$ post-transfection, the medium was replaced with fresh media containing $10 \%(\mathrm{w} / \mathrm{v})$ FBS and $10 \%$ rezasurin and incubated for another $3 \mathrm{~h}$. Fluorescence $(\lambda \mathrm{ex}=530 \mathrm{~nm}, \lambda \mathrm{em}=590 \mathrm{~nm})$ was measured in a micro-plate reader (SynergyMx, Biotek). The viability of cells exposed to dendritic copolymer was expressed as a percentage of the viability of non-treated cells. The presented data are expressed as the mean $\pm \mathrm{SD}$ of three independent sample measurements. 


\subsection{Cellular uptake}

Flow cytometry. U2OS/eGFPLuc cells were seeded in 24-well plates at a density of $2.6 \times 10^{4} \mathrm{cells} / \mathrm{cm}^{2}$ and incubated for $24 \mathrm{~h}$ in supplemented DMEM medium at $37{ }^{\circ} \mathrm{C}, 5 \% \mathrm{CO}_{2}$, and grown to reach $70-80 \%$ confluence prior to transfection. At the time of transfection, the medium was replaced with nonsupplemented DMEM. Dendriplexes were prepared with Cy-5 labeled siRNA as previously described. Cells were then transfected using $50 \mu \mathrm{L}$ dendriplexes in a final volume of $300 \mu \mathrm{L}$ (siRNA concentration of $0.1 \mathrm{pmol} / \mu \mathrm{L}$ ). After $24 \mathrm{~h}$ incubation, cells were rinsed twice with $1 \mathrm{x}$ PBS, trypsinized, centrifuged, resuspended in 1x PBS 2\% FBS and analyzed by flow cytometry (FACSCalibur, BD Biosciences). Nontreated cells and cells transfected with Lipofectamine ${ }^{\circledR} 2000$ (L2k, Life Technologies) following the manufacturer's instructions were used as negative and positive controls, respectively. Data was analyzed using FlowJo software (version 8.3.7).

Imaging flow cytometry. U2OS cells were seeded in $24-w e l l$ plates at a density of $2.6 \times 10^{4} \mathrm{cells} / \mathrm{cm}^{2}$, incubated for $24 \mathrm{~h}$ in supplemented DMEM medium at $37^{\circ} \mathrm{C}, 5 \% \mathrm{CO}_{2}$, and grown to a confluence of 70 $80 \%$ prior to transfection. At the time of transfection, the medium was replaced by non-supplemented DMEM. siRNAmi dendriplexes at N/P 160 were prepared using Cy-5 labeled siRNAmi. Cells were then transfected with a final volume of $350 \mu \mathrm{L}$ (final siRNAmi concentration $0.1 \mathrm{pmol} / \mu \mathrm{L}$ ). $24 \mathrm{~h}$ after incubation, cells were rinsed once with PBS 1x and trypsinized. Cells were then transferred to Eppendorfs and centrifuged for $5 \mathrm{~min}$ at $1200 \mathrm{rpm}$ at $4^{\circ} \mathrm{C}$. After washing with PBS $1 \mathrm{X}$, cells were centrifuged (5 min at $1200 \mathrm{rpm}$ at $4^{\circ} \mathrm{C}$ ), and subsequently fixed with $4 \%$ paraformaldehyde (PFA) for 15 minutes. After fixation, cells were washed twice with PBS 1x.

Cell images were acquired using an imaging flow cytometer (ImageStream ${ }^{\circledR}$, Amnis, EDM Millipore, Darmstadt, Germany) at a magnification of 40x. A $488 \mathrm{~nm}$ wavelength laser was used to excite Cy-5 labeled siRNAmi. The fluorescence images were collected using the 660-745 $\mathrm{nm}$ spectral detection channel. Images were also acquired using the Extended Depth of Field (EDF) filter. Data was subsequently analyzed using IDEAS v6.1 image-analysis software (Amnis Corporation, EDM Millipore). Each cell was divided into 2 regions - external (membrane) and internal (cytoplasm). A first mask was applied that covered the entire cell. The external region was determined by dilating the mask by the membrane thickness. The internal region was defined by the mask of the whole cell minus the cell membrane mask. A mask was then attributed to the intensity of the Cy5 channel. The intensity mask was merged with the cytoplasm (internal) mask, which allowed filtering cells for positive internalization. To determine the number of vesicle-loaded dendriplexes, masks were created which identify the fluorescent 
spots. The number of individual vesicles in a cell was enumerated using the Spot Count feature from the IDEAS v6.1 software, and plotted in frequency histograms (Figure S17). Three regions (low, medium and high spot count) were defined based on the worst performing copolymer (hsD). The region for medium spot count was defined as mean spot count for hsD (3.5) \pm its corresponding standard deviation (2). The low spot count region is below $3.5-2$ and the high spot region is above $3.5+2$.

Confocal Microscopy. U2OS/eGFPLuc cells were seeded in $\mu$-Slide 8-wells ibiTreat (Ibidi) at a cell density of $2 \times 10^{4}$ cells $/ \mathrm{cm}^{2}$ and incubated for $24 \mathrm{~h}$ in supplemented DMEM medium at $37{ }^{\circ} \mathrm{C}, 5 \% \mathrm{CO} 2$, and grown to reach 50-60\% confluence prior to transfection. At the time of transfection, the medium was replaced with non-supplemented DMEM. bD/siRNAmi and bB/siRNAmi dendriplexes with N/P ratios of 160 were prepared using Cy-5 labeled siRNAmi. Cells were then transfected using $50 \mu \mathrm{L}$ dendriplexes in a final volume of $300 \mu \mathrm{L}$ (siRNAmi concentration of $0.1 \mathrm{pmol} / \mu \mathrm{L}$ ). After $24 \mathrm{~h}$, transfected cells were washed three times with PBS and incubated $10 \mathrm{~min}$ at RT with a 1:20,000 diluted solution of Hoechst 33342 (10 mg/mL, Life technologies) for nuclear staining. Cells were then washed with PBS and OptiMEM (no phenol-red) was added to cells prior to microscopy. Cells were imaged with a Leica TCS SP2 AOBS confocal microscope. Three-dimensional z-stacks were captured and processed using ImageJ $1.49 \mathrm{~K}$ software (NIH, USA).

\subsection{Silencing studies}

U2OS/eGFPLuc cells were seeded in 24-well plates at a density of $2.6 \times 10^{4}$ cells $/ \mathrm{cm}^{2}$ and incubated for $24 \mathrm{~h}$ in supplemented DMEM medium at $37{ }^{\circ} \mathrm{C}, 5 \% \mathrm{CO} 2$, and grown to reach $70-80 \%$ confluence prior to transfection. At the time of transfection, the medium was replaced with non-supplemented DMEM. Dendriplexes with N/P ratios of 160 were prepared as previously described. Cells were then transfected using $50 \mu \mathrm{L}$ dendriplexes in a final volume of $300 \mu \mathrm{L}$ (siRNA concentration of $0.1 \mathrm{pmol} / \mu \mathrm{L}$ ). After $24 \mathrm{~h}$ incubation, cells were treated with chloroquine $(\mathrm{CQ}, 100 \mu \mathrm{M})$ and further incubated for $4 \mathrm{~h}$. Medium was then replaced with fresh supplemented DMEM and incubated another $44 \mathrm{~h}$. Cells were rinsed twice with PBS and then incubated on ice with $0.15 \%$ Triton X-100 HKR buffer for 5 min. Cell lysates were centrifuged at $400 \mathrm{~g}$ for $5 \mathrm{~min}$ and supernatants were further analyzed for luciferase activity with Promega's luciferase assay reagent following the supplier's instructions. Luminescence was measured using a micro-plate reader (SynergyMx, Biotek). Protein concentration in cell lysates was measured using the BSA Protein Assay Kit (Pierce, Thermo Scientific). Luciferase activity of treated cells was expressed as the percentage of luciferase activity relative to non-treated cells. The same protocol was used for the 
experiments with $\mathrm{bD} / \mathrm{siRNA}$ dendriplexes at different N/P ratios. The presented data are expressed as the mean $\pm \mathrm{SD}$ of four $(\mathrm{n}=4)$ independent sample measurements.

\subsection{Statistical analysis}

Data are given as mean \pm standard deviation (SD), with $n$ denoting the number of repeats. Significant differences were examined using one-way ANOVA. Tukey's multiple comparison test was further employed after one-way ANOVA for samples were homogeneity of variances was observed. GamesHowell multiple comparison test was employed after Welch ANOVA for samples violating homogeneity of variances. A $p$ value of $<0.05$ was considered statistically significant in all studies. Statistical analyses were performed using IBM SPSS Statistics 21 software.

\section{RESULTS AND DISCUSSION}

\subsection{Design, Synthesis and Characterization of Hybrid-Biodegradable PEG-GATGE Block Copolymers}

In dendriplexes, the primary interaction between dendritic species and NAs is electrostatic (positively charged dendrimers and negatively charged phosphate groups at the NA). Consequently, dendriplex stability and NA delivery profile usually improve with the dendritic generation (G). ${ }^{6}$ In GATG, however, no significant differences in terms of cellular uptake and transfection efficiency for pDNA have been observed between G2 and G3. ${ }^{21}$ Similar results have been also reported for PPI, where even better gene transfers were obtained for lower generations (G2) ${ }^{49}$ In this scenario and considering the accelerated access and enhanced biocompatibility of lower $\mathrm{G}$, we decided to focus our attention on the synthesis and evaluation of the siRNA delivery properties of G2 PEG-GATGE copolymers (PEG-b[G2]). To minimize undesired and premature degradation during synthesis, purification, functionalization with amine groups (which will be able to react by intramolecular side-reactions with electrophilic ester groups) and subsequent application, ${ }^{35,36}$ a hybrid dendritic copolymer was planned combining a classical GATG unit at the core (depicted in blue in Figure 1a) surrounded by a shell of novel biodegradable GATGE units (green in Figure 1a). PEG-GATGE dendritic block copolymers present important advantages to act as suitable carriers in nanomedicine for the encapsulation and delivery of different therapeutic drugs. Namely, the combination of hydrophobic (gallic acid and the aliphatic ester spacer, depicted in pink in Figure 2a) and hydrophilic character (triethylene glycol) in the same building unit. Moreover, defining the localization of the degradation sites at the dendritic arms/periphery, in close contact to the carried drug 
(siRNA, in this case), follows to enhance its intracellular release and transfection efficiency (in the NA cases) compared to other non-biodegradable systems, such as the hydrolytically stable PEG-GATG counterparts.

The synthesis of the GATGE unit $\mathbf{5}$ comprising a gallic acid core and triethylene glycol-aliphatic ester arms is shown in Figure 2a. One relevant aspect of the proposed synthetic route is that allows facile structural modifications and, therefore, a suitable degradability tuning by changing the length/nature of the ester spacer (depicted in pink in Figure 2a). Despite the presence of degradable/hydrolyzable ester bonds hinders its synthesis, building unit $\mathbf{5}$ was efficiently synthesized from commercially available chlorotriethylene glycol (3), 4-bromobutanoic acid and gallic acid (1). Initial treatment of 4bromobutanoic acid with azidetriethylene glycol (easily obtained from $\mathbf{3}$ and $\left.\mathrm{NaN}_{3}\right)^{47}$ with DCC and DMAP led to ester 4 in an excellent $97 \%$ combined yield. Subsequent coupling of 4 with tert-butyl gallate (2) $\left(\mathrm{K}_{2} \mathrm{CO}_{3}, 18 \mathrm{C} 6\right)$ followed by a selective hydrolysis of the tert-butyl ester afforded the desired biodegradable building unit 5 in $82 \%$ overall yield (Figure 2a).

Envisaging PEG-GATGE copolymers as NA vectors, preliminary degradability tests were performed on a readily accessible GATGE unit $6\left(\mathrm{H}_{2}, \mathrm{Pd} / \mathrm{C}\right)$, which incorporates terminal primary amino groups as cationic surrogates to mimic the cationic character envisaged for the NA complexation. As seen in Figure $2 \mathrm{~b}$, degradation studies were carried out in simulating physiological and endosomal $\mathrm{pH}$ conditions (7.4 and 5.0, respectively; $37^{\circ} \mathrm{C}$ ) afforded hydrolysis of the ester bonds in a time-dependent fashion. Higher degradation rate was obtained at pD 7.4 than 5.0 (Figure 2b, experiments conducted in deuterated water). This observation can be explained because in deuterated water the hydrolysis reaction is catalyzed at basic $\mathrm{pH}$ (see Figure S17, SI). However, it is worthwhile mentioning that intracellularly one could expect higher hydrolysis rates at lower $\mathrm{pH}$ (as in the case of endosomal $\mathrm{pH}$ ), since acid catalyzed degradation in water can occur up to thrice faster than in deuterated water $\left(\mathrm{D}_{2} \mathrm{O}\right) .{ }^{50}$ 
a)
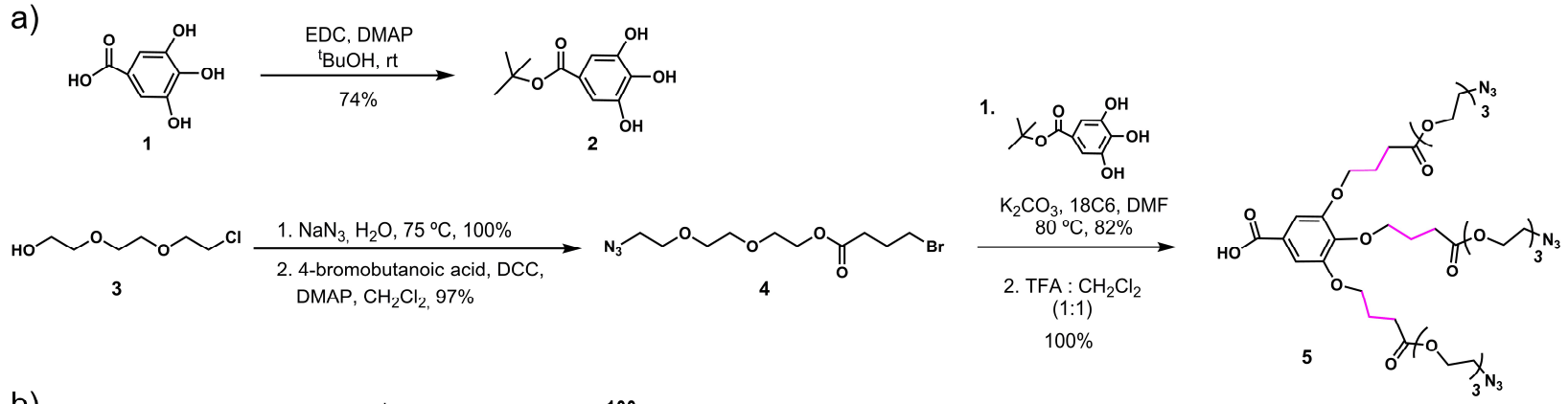

b)
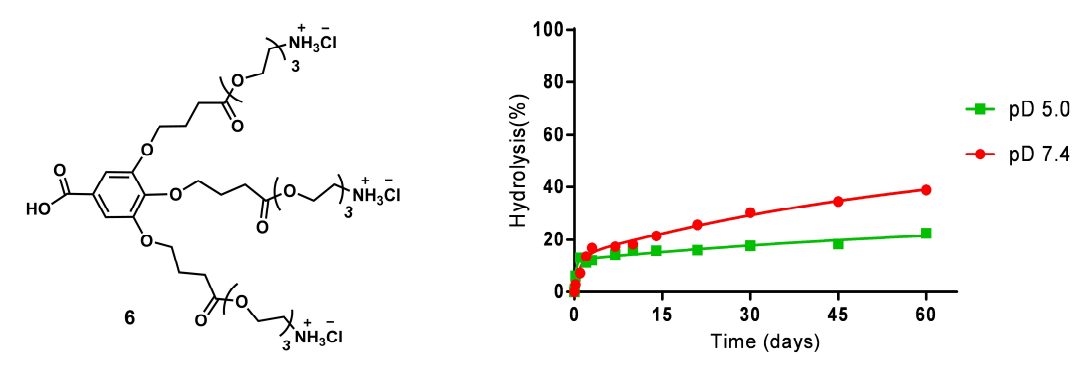

Figure 2. a) Synthesis of biodegradable GATGE building unit 5. b) Kinetics of the ester hydrolysis in the amine-terminated unit 6 by ${ }^{1} \mathrm{H}$ NMR at pD 5.0 and 7.4.

With a reliable synthesis of $\mathbf{5}$ in hand, the preparation of PEG-GATGE copolymers was addressed following a divergent strategy starting from a monomethyl ether PEG amino $\left(\mathrm{PEG}-\mathrm{NH}_{2} \cdot \mathrm{HCl}, \mathrm{Mn}=5079\right.$, $\mathrm{Mw}=5113$, PDI $=1.007)$ and the GATG unit (7) (Scheme 1). ${ }^{47}$ In this way, the block copolymer PEG$[\mathrm{G} 1]-\mathrm{N}_{3}(\mathbf{8})$ was readily obtained (EDC, $\mathrm{HOBt}$ ) in an excellent $93 \%$ yield after purification by precipitation thanks to the properties of PEG as a soluble polymeric support (Scheme 1). Catalytic hydrogenation of the terminal azides in $\mathbf{8}$, followed by treatment of the resulting triamine with $\mathbf{5}$ (EDC, $\mathrm{HOBt}$ ) led to the desired PEG-b[G2]-N 3 (9) in $86 \%$ yield (Scheme 1).

Block copolymer 9 was completely characterized by ${ }^{1} \mathrm{H}$ and ${ }^{13} \mathrm{C}$ NMR (1D and 2D), MALDI-TOF MS and FTIR (Section 2.2 and Figures S7, S14 and S15 of the SI). The dendritic growth was monitored by ${ }^{1} \mathrm{H}-\mathrm{NMR}$ spectroscopy $\left(\mathrm{CD}_{2} \mathrm{Cl}_{2}\right)$ by following the appearance of the signals corresponding to the butanoate spacer (protons $h, i, j$ ) and those adjacent to the azide groups ( $l$ and $l$ ': 3.31-3.35 ppm) (Scheme 1), as well as by the disappearance of the signals corresponding to the methylene protons adjacent to the amine groups (2.72-2.78 ppm) (Figure S6, SI). The MALDI-TOF spectrum of 9 shows a Gaussian distribution of peaks corresponding to the block copolymer adducts with sodium, spaced by 44 Da that correspond to the expected PEG oligomers (Figure S14, SI). Experimental Mp, Mw and Mn were in agreement with calculated values. FTIR spectroscopy clearly revealed the presence in $\mathbf{9}$ of characteristic peaks at 1736 and $2110 \mathrm{~cm}^{-1}$ corresponding to the ester and azide groups (Figure S15, SI). 


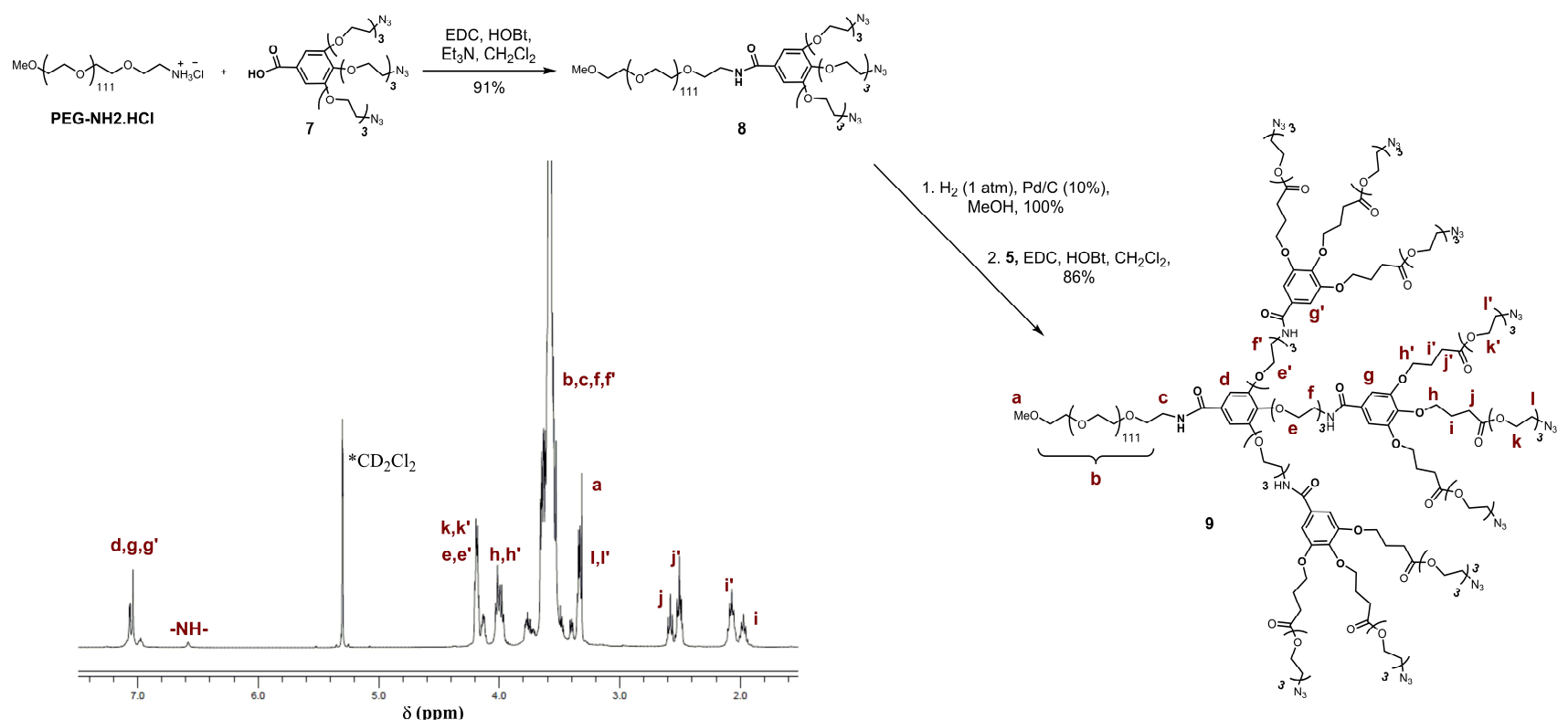

\subsection{Multivalent Functionalization of Hybrid-Biodegradable PEG-GATGE Copolymer with}

\section{Unprotected Amines by CuAAC}

The cationic nature of amines at physiological $\mathrm{pH}$ is usually exploited to enable the ionic condensation and protection of NAs within dendriplexes. As already mentioned, we have previously proposed amineterminated GATG dendrimers and their PEGylated copolymers as pDNA vectors. However, the use of the same copolymers for siRNA delivery resulted in very limited internalization efficiency with only a 23 $\%$ of positive cells (data not shown), probably related to a deficient stability of the dendriplexes. It is worth mentioning that fundamental differences between pDNA and siRNA molecules regarding size, morphology, flexibility and charge, can result in a less efficient interaction and lower protection of the latter. ${ }^{51}$ Thus, commonly used cationic vectors for gene delivery do not necessarily result in optimal siRNA vectors. ${ }^{52-54}$ Here, we demonstrate that after CuAAC functionalization with alkynated propylenediamine (10) and benzylamine (11) ligands (Figure 3a), cationic PEG-GATG and PEG-GATGE copolymers enable the efficient complexation of siRNA and its delivery into cells. The selection of alkynated ligands was inspired by our results on the stability of polyion complex (PIC) micelles derived from PEG-GATG copolymers carrying peripheral triazol groups. ${ }^{55,56}$ While the use of the diamine (10) aimed to boost the dendrimer-siRNA binding strength by increasing the positive multivalency, the benzylamine ${ }^{56}$ (11) seeks to increase further the hydrophobicity of the system. Hydrophobia is very 
important for the current application (nucleic acid delivery), since although electrostatic interactions are the most important in assuring the stability of the dendriplexes, the contribution of hydrophobic interactions cannot be neglected.

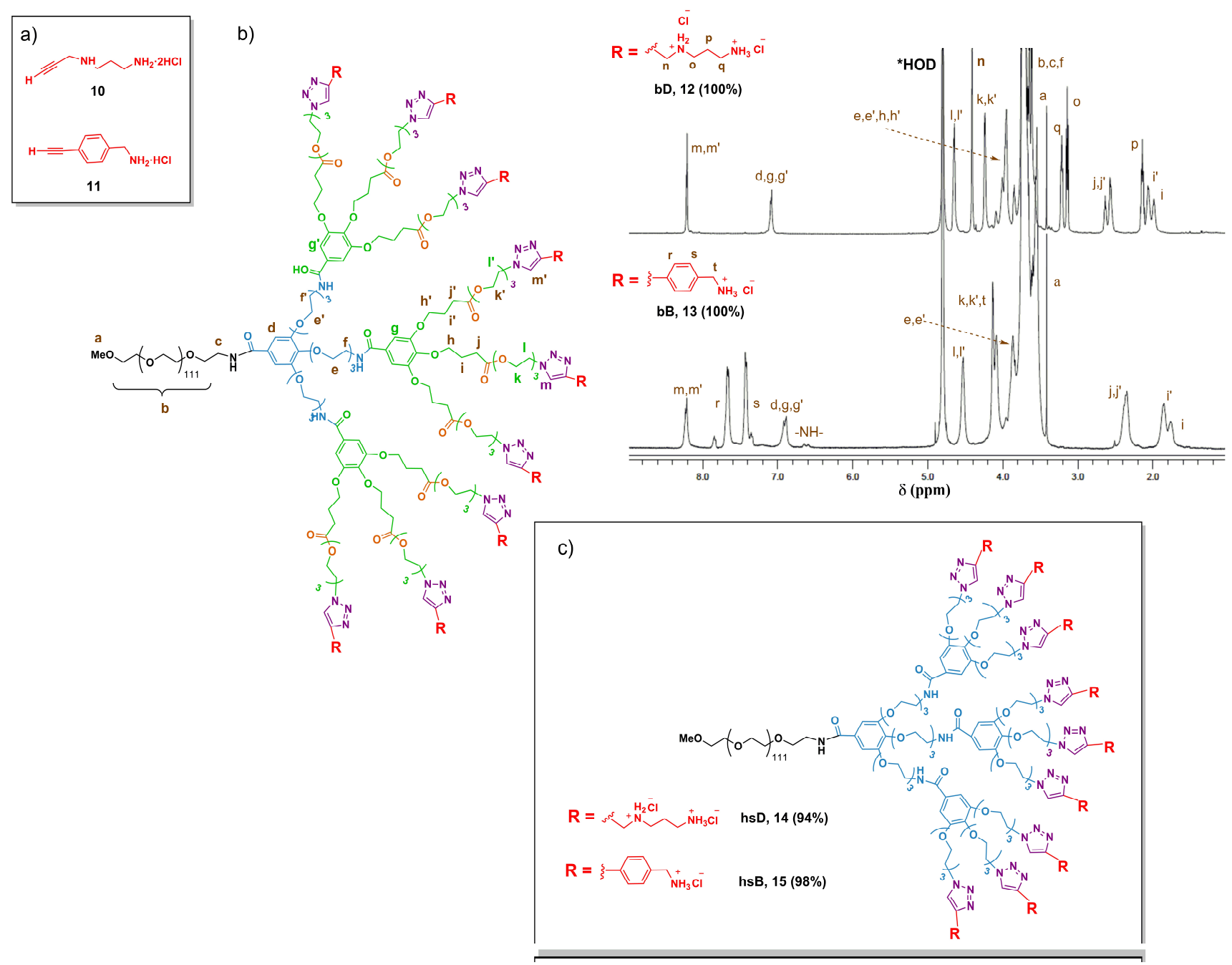

Figure 3. a) Structures of alkynated propylenediamine (10) and benzylamine (11) ligands. b) Structures and ${ }^{1} \mathrm{H}$ NMR spectra $\left(400 \mathrm{MHz}, \mathrm{D}_{2} \mathrm{O}\right)$ of amine-terminated bD (12) and bB (13). c) Structures of hydrolytically stable hsD (14) and hsB (15).

The functionalization of PEG-b[G2]- $\mathrm{N}_{3}$ was carried out with the alkynated ammonium salts $\mathbf{1 0}$ and $\mathbf{1 1}$ as a means to mask their nucleophilicity and avoid degradation by side-reaction with the ester groups. $\mathrm{CuAAC}$ was performed with $\mathrm{CuSO}_{4}(5 \mathrm{~mol} \%$ per azide) and sodium ascorbate ( $25 \mathrm{~mol} \%$ per azide) in DMF: $\mathrm{H}_{2} \mathrm{O}$ 1:1 (RT, $\left.12 \mathrm{~h}\right)$. The resulting diamine- and benzylamine-terminated copolymers bD (12) and bB (13) were obtained in quantitative yields after purification by ultrafiltration (Figure 3b). Completion of the conjugation was monitored by ${ }^{1} \mathrm{H}$ NMR $\left(\mathrm{D}_{2} \mathrm{O}\right)$ thanks to the disappearance of the signal of the methylene protons adjacent to the azide group (Figure $3 \mathrm{~b}$ ), and FTIR by disappearance of the azide band 
$\left(2101 \mathrm{~cm}^{-1}\right)$ (Figure S16). Successful coupling was also confirmed in ${ }^{1} \mathrm{H}$ NMR by appearance of: a signal around $8.20 \mathrm{ppm}$ corresponding to the triazol protons ( $m$ and $m$ '), a multiplet around 4.5-4.7 ppm due to the protons in alpha to the triazol group $(l$ and $l$ '), as well as for the characteristic signals of the amine ligands (n,o,p and $q$ for 12, and $r, s$ and $t$ for 13) (Figure 3b). Following similar reaction conditions, amine-terminated copolymers $\mathbf{1 4}$ and $\mathbf{1 5}$ derived from the hydrolytically stable PEG-GATG copolymer of G2 were also synthesized as controls for siRNA delivery assays (Figure 3c). Details about their synthesis and characterization can be found in Section 2.2 and Figures S10-S13 of the SI.

Similarly, to the studies performed for the GATGE unit 6, degradability tests were carried out for the biodegradable copolymers bD (12) and bB (13). Qualitative NMR data analysis also point to the degradation of these dendritic copolymers over time at pD 7.4 (Figure S18, SI), since significant changes, which indicate the instability/degradability of the proposed dendritic copolymers under simulated physiological conditions, can be clearly observed on the spectra. These changes include alterations on the signals intensity and/or shape, as well as appearance and/or disappearance of signals corresponding to the protons of the degraded products and new fragments.

\subsection{Preparation and Characterization of Dendriplexes}

The association of the amine-terminated copolymers 12-15 with siRNA was studied and the physicochemical properties of the resulting dendriplexes evaluated. For the experiments where biological activity is not assessed, a double stranded DNA of exact same sequence as anti-enhanced green fluorescence protein siRNA (anti-eGFP siRNA) was used for mimicking siRNA (siRNAmi) for its ease of synthesis and possibility to obtain in higher yields and purity.

3.3.1. siRNA Binding Ability. The interaction strength of the copolymers with the siRNAmi was initially assessed by polyacrylamide gel retardation assay (PAGE), which for short NA gives a higher resolution compared to traditional agarose gels. As shown in Figure 4a, the amount of free siRNAmi that migrates in the gel decreased as increasing amounts of copolymers were used (N/P charge ratios ranged from 20 to 160). The charge ratio (N/P) was defined as the ratio between the maximum number of protonable primary amines in the dendritic copolymer and the number of negative phosphates in siRNA or siRNAmi.

The complexation efficiency of the copolymers was studied by a nucleic acid dye (SYBRGold ${ }^{\circledR}$ ) accessibility assay. SYBRGold ${ }^{\circledR}$ is a very sensitive fluorescent dye for the detection of NAs. It is cationic and after binding NA presents a very high fluorescence enhancement, a property that can be used to distinguish between free and complexed (inaccessible) NAs. As shown in Figure 4b, although differences 
are not statistically significant, the amount of complexed siRNAmi increases with N/P. Complexation was $\geq 70 \%$ for all copolymers in the whole $\mathrm{N} / \mathrm{P}$ range analyzed, with values $>80 \%$ at $\mathrm{N} / \mathrm{P} \geq 40$. As expected, both PAGE and SYBRGold ${ }^{\circledR}$ assays show the diamine-terminated (D) as the most effective group for retaining and complexing siRNAmi because of the divalent character of the diamine. As for the dendritic framework, the incorporation of the GATGE building unit resulted in a more efficient complexation probably due to the hydrophobic spacers contributing to an enhanced siRNA packaging. Altogether, bD resulted the most efficient copolymer in terms of siRNAmi complexation, with around $90 \%$ of siRNAmi complexed even at the lowest N/P values studied.

a)

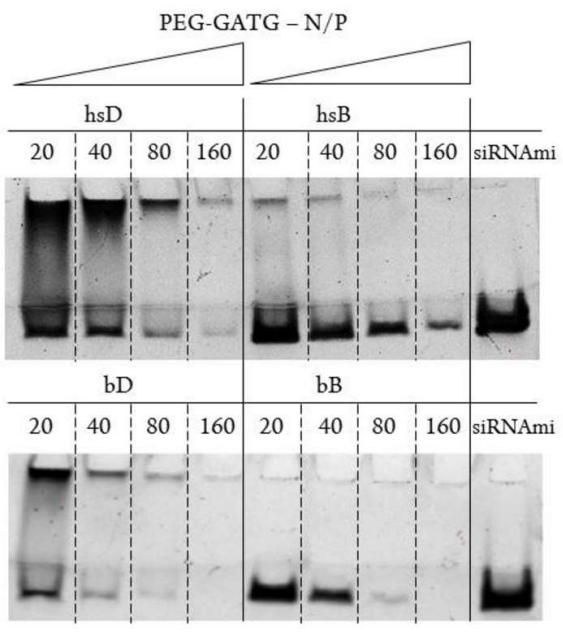

b)

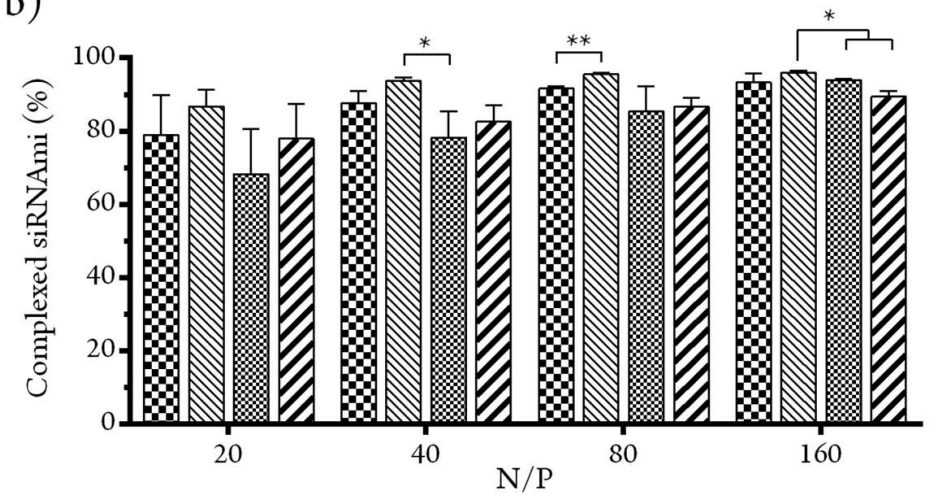

$\mathbf{B} \mathrm{hsD} \mathrm{bD} \approx \mathrm{hsB} \mathbb{\mathrm { bB }}$

Figure 4. a) Polyacrylamide gel retention assay (PAGE) of the siRNAmi dendriplexes from: hydrolytically stable PEG-GATG (hsD and hsB) and hybrid-biodegradable PEG-GATGE (bD and bB) at different N/P. b) SYBRGold ${ }^{\mathbb{R}}$ exclusion assay at RT. One-way ANOVA tests were used for statistical analysis. Significant differences: $* p<0.05, * * p<0.01$. Significant differences between N/P's: hsB 20 vs. hsB $160(\mathrm{p}<0.05)$.

3.3.2. Size and Morphology. Dendriplexes were characterized in terms of size and morphology using dynamic light scattering (DLS) and transmission electron microscopy (TEM), respectively. Regardless of the dendritic copolymers, a narrow particle size distribution in the nanometer scale was obtained for all N/P tested, with suitable size and polydispersity for cellular uptake. ${ }^{7,} 57$ Furthermore, both size and PDI were found to be independent of the N/P. Dendriplexes of average size around $145 \mathrm{~nm}$ were obtained for the diamine series and $175 \mathrm{~nm}$ for the benzylamine one (Figures 5a and 5c). Dendriplex population was slightly more homogenous for the benzylamine than diamine copolymers (PDI around 0.3 and 0.4, respectively, Figure $5 \mathrm{~b}$ ). Thus, to compare the stability of the dendriplexes based on both terminal amine groups (diamine and benzylamine), sizes of the biodegradable dendriplexes at N/P 80 and 160, were 
measured after 1, 4 and $8 \mathrm{~h}$ of incubation in PBS containing 20\% (v/v) of FBS (Figure S19, SI). The peak intensity versus size profile obtained indicates that the incubation of the $\mathrm{bD}$ dendriplexes in the presence of serum induced a decrease of the maximum peak intensity, an increase of the peak width and a shift toward increased sizes. However, no significant differences were observed for $b B$ dendriplexes, pointing to the high stability of this system. When the size of the dendriplexes (N/P 80 and 160) were studied as a function of $\mathrm{pH}$ (Figure S20, SI) at different time points (1, 4 and $8 \mathrm{~h}$ ), no significant differences were observed for all formulations at $\mathrm{pH} 7.4$, when analyzing the peak of higher intensity (Figure S20b, SI). While at $\mathrm{pH} 5$, a slight shift of the dendriplex population toward increased sizes was observed (Figure S20a, SI). These alterations were less notable for bB dendriplexes, indicating, again, their higher stability. In all cases, it was observed the appearance of smaller populations, which we ascribe to the appearance of dendriplex degradation sub-products. Under these conditions, these can be distinguished due to the absence of other larger molecules (as in the case of the data previously discussed, Figure S19, SI where the characterization was performed in the presence of FBS).

As shown in the TEM images (Figure 5e), all dendriplexes show spherical and compact structures with sizes that correlate well with those obtained by DLS (Figure 5a).

Another important parameter for the cellular activity of the transfection dendriplexes is their capacity to release the siRNA once inside the cell. Thus, to test the reversibility of dendriplex formation, biodegradable dendriplexes were incubated at $37{ }^{\circ} \mathrm{C}$ and at physiological salt and $\mathrm{pH}$ conditions with heparin, a model polyanion commonly used to test destabilization and release of nucleic acids from dendriplexes. ${ }^{54,58} \mathrm{bD}$ and $\mathrm{bB}$ dendriplexes (N/P ratio 160) were tested, with an extensive release of siRNA being observed when these challenged with increased concentrations of heparin (Figure S21, SI).

Taken together, these results and the dendriplexes' stability in the presence of serum and as a function of $\mathrm{pH}$, one can conclude that there is a good equilibrium in terms of extracellular stability and intracellular siRNA release, especially for the bB-based dendriplexes. The importance of the hydrophobic interactions between vector and NA seems to emerge again from all these results with terminal aromatic groups leading to more homogeneous and stable dendriplexes.

3.3.3. Zeta Potential. The surface charge of the dendriplexes in water was measured by laser Doppler electrophoresis (Figure 5d). For all tested formulations, the dendriplexes net charge was positive, with diamine dendriplexes presenting higher zeta potentials (ca. $20 \mathrm{mV}$ at $\mathrm{N} / \mathrm{P} \geq 40$ ) compared to benzylamine (ca. $10 \mathrm{mV}$ for all $\mathrm{N} / \mathrm{P}$ tested) in agreement with the expected higher density of positive charges. The 
different values observed for diamine derivatives ( $\mathrm{bD}$ and $\mathrm{hsD}$ ) are probable related to the different packaging of the particles (Figure 5d).

a)

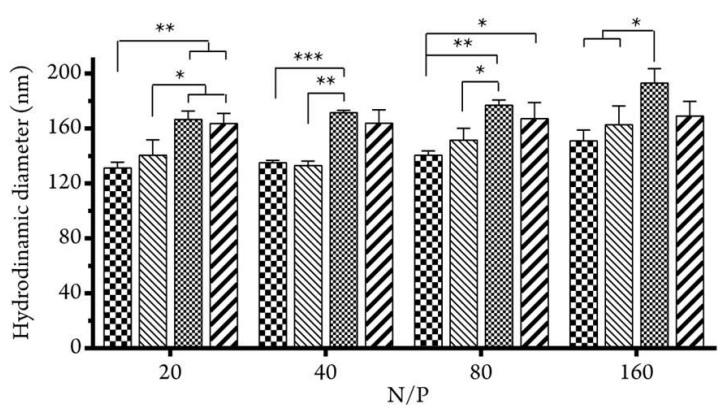

c)
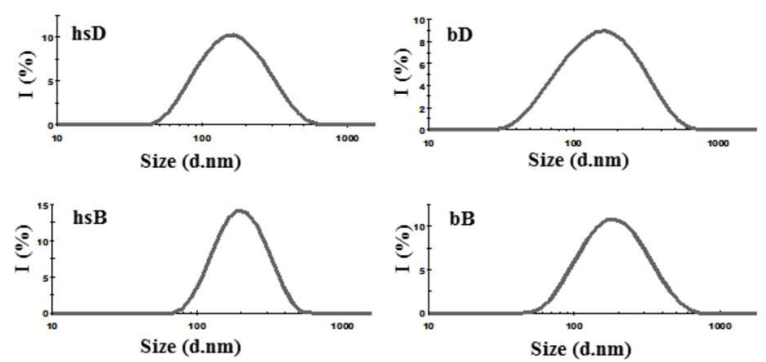

$\mathbf{B}$ hsD bD b)

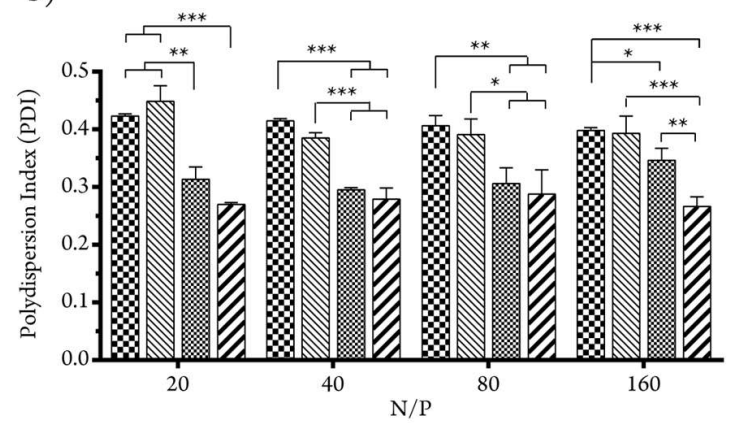

d)

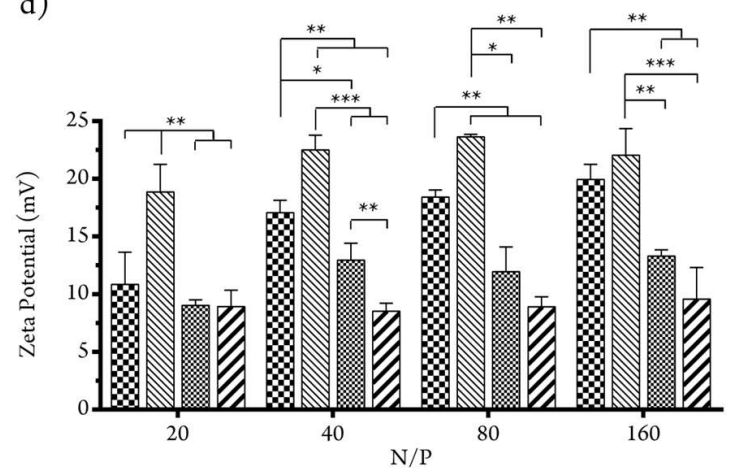

e)

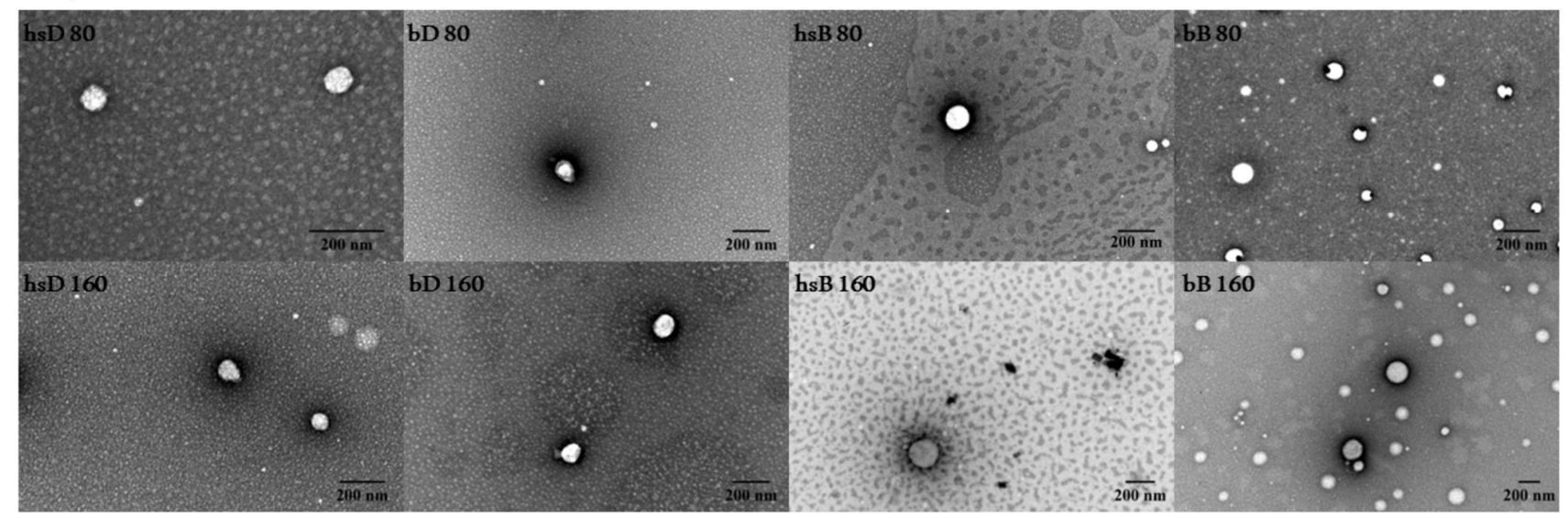

Figure 5. a) Size distribution of siRNAmi dendriplexes measured by DLS at different N/P ratios ( $\mathrm{n}=3, \pm$ SD). Significant differences between N/P's: bD 40 vs. bD 160 ( $p<0.05)$. b) Polydispersity index (PDI) of siRNAmi dendriplexes measured by DLS at different N/P ratios $(n=3, \pm S D)$. No significant differences between N/P's. c) Representative size siRNAmi dendriplexes (N/P 80) measurements using DLS: hsD (Z-Average: $141 \mathrm{~nm}$, PDI: 0.38); bD (Z-Average: $134 \mathrm{~nm}$, PDI: 0.38); hsB (Z-Average: 168 nm, PDI: 0.24); bB (Z-Average: $163 \mathrm{~nm}$, PDI: 0.26). d) Potential zeta values for all developed dendriplexes at different N/P ratios. Significant differences between N/P's: bD 20 vs. bD 80 (p < 0.05), hsD 20 vs. hsD 40/80/160 ( $p<0.01)$, hsB 20 vs. hsB 160 ( $p<0.01)$. Dendriplex characterization data in nuclease free 
water. e) TEM images for siRNAmi dendriplexes at N/P 80 and 160: hsD, hsB, bD, and bB. Significant differences: ${ }^{*} \mathrm{p}<0.05,{ }^{*} \mathrm{p}<0.01$ and $* * * \mathrm{p}<0.001$. One-way ANOVA tests were used for statistical analysis.

3.3.4. Dendriplexes degradation studies. In order to assess the siRNA released from the dendriplexes as a function of the time and at different $\mathrm{pHs}, \mathrm{bD}$ and $\mathrm{bB}$ siRNA dendriplexes were incubated under acidic ( $\mathrm{pH}$ 5.0) and physiological (pH 7.4) $\mathrm{pH}$ conditions for 1, 24 and $48 \mathrm{~h}$. After that, dendriplexes were treated with heparin and the amount of siRNA released was determined by PAGE. The results show that a significant amount of siRNA has been released even after $1 \mathrm{~h}$ of incubation (Figure S22, SI). This was particularly noteworthy at $\mathrm{pH} 7.4$, in agreement with the higher percentage of degradation observed for the GATGE unit 6 (Figure 2b) at pD 7.4.

Observing the degradation studies as a whole, it could be concluded that the hydrolysis rate for the dendritic structures (section 3.1 and Figure 2b, section 3.2, and Figure S18, SI) is slower than those for the dendriplexes. However, one must take into consideration that buffers for both experiments are prepared in different isotopic types of water: deuterated water for the degradability studies by NMR of the dendritic structures, while "normal" water was used for the dendriplex degradation studies by PAGE. As previously discussed, the catalysis rate can be significantly different in both media due to the kinetic isotope effect. ${ }^{50}$ Moreover, and regardless of this isotopic effect, only a "low" percentage of degradation in the arms of each PEG-dendritic block copolymer can lead to a "high" instability of the dendriplexes (formed between several PEG-GATGE molecules and several siRNA molecules), which in turn can lead to a significant amount of released siRNA, as showed in Figure S22, SI.

Overall these results confirm that the functionalization of the copolymers with both amine groups results in well-defined dendriplexes, with suitable properties for cellular uptake and siRNA delivery.

\subsection{Biological performance evaluation}

All copolymers were further evaluated regarding their cytotoxicity, ability to protect siRNA from endonuclease degradation and transfection efficiency.

3.4.1. Cell Metabolic Activity/Cellular Toxicity. Given that toxicity can represent a hurdle for the implementation of macromolecular systems in biomedicine, the cytotoxicity of the copolymers and dendriplexes was assessed in human osteosarcoma U2OS cells. Cytotoxicity was evaluated in terms of 
alterations in cell metabolic activity via a resazurin-based assay. For free azide- and amine-terminated copolymers $(\mathbf{9}, 12,13,14$ and 15), the concentrations evaluated ranged between 0.25 and $1.5 \mathrm{mg} / \mathrm{mL}$ (Figure 6a). In all cases, after $24 \mathrm{~h}$ of incubation, cell metabolic activity was higher than $85 \%$, which indicates a low cytotoxic profile for these copolymers, even after functionalization with positive terminal groups. Subsequently, the toxicity of the dendriplexes potentially more toxic to the cells (N/P ratios of 80 and 160) was also tested. Here again, viabilities higher than $90 \%$ were obtained in all cases (Figure 6b).

a)

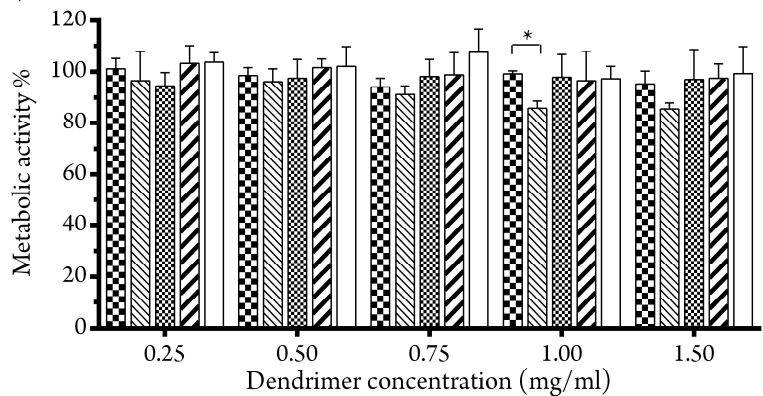

b)

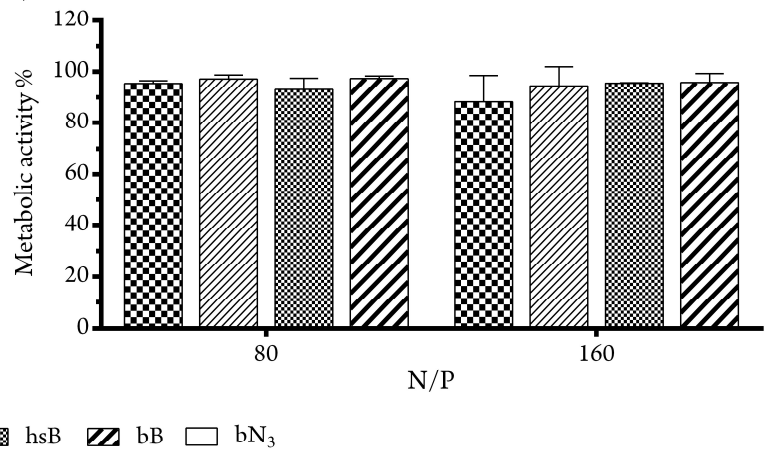

Figure 6. Relative metabolic activity (resazurin assay) using non-treated cells as a reference determined upon $24 \mathrm{~h}$ incubation of U2OS cells with: a) PEG-GATGE and PEG-GATG dendritic copolymers: azideand amine-terminated. b) Dendriplexes at N/P 80 and 160 (equivalent to a copolymer concentration ca. 0.5 and $1 \mathrm{mg} / \mathrm{mL}$, respectively). One-way ANOVA tests were used for statistical analysis. Significant differences: $* \mathrm{p}<0.05$.

3.4.2. Endonuclease protection. siRNA protection from endogenous nucleases is a critical parameter in the development of new NA vectors. To this end, dendriplexes prepared from the four copolymers and siRNAmi at N/P 160 were incubated with an endonuclease for different periods (5-60 min). Then, after siRNAmi was displaced from the complexes with sodium dodecyl sulfate, samples were analyzed by PAGE (Figure 7). While naked NA was completely degraded within $5 \mathrm{~min}$, various degrees of siRNAmi protection were observed for the complexes with time. bB showed the highest protection capacity, with a notable level of unaffected siRNAmi even seen after $60 \mathrm{~min}$ of incubation. This points again to the relevance of the extra hydrophobic contribution provided by the aromatic benzylamine (B), that together with the hydrophobic spacers in GATGE, provide a very good protection of NA from degradation.

Previous studies showed that amine-terminated PEG-GATG were not able to protect pDNA from degradation for periods longer than $5 \mathrm{~min} .{ }^{21}$ The present results demonstrate the benefit of the peripheral functionalization with these aminated groups in this regard. 


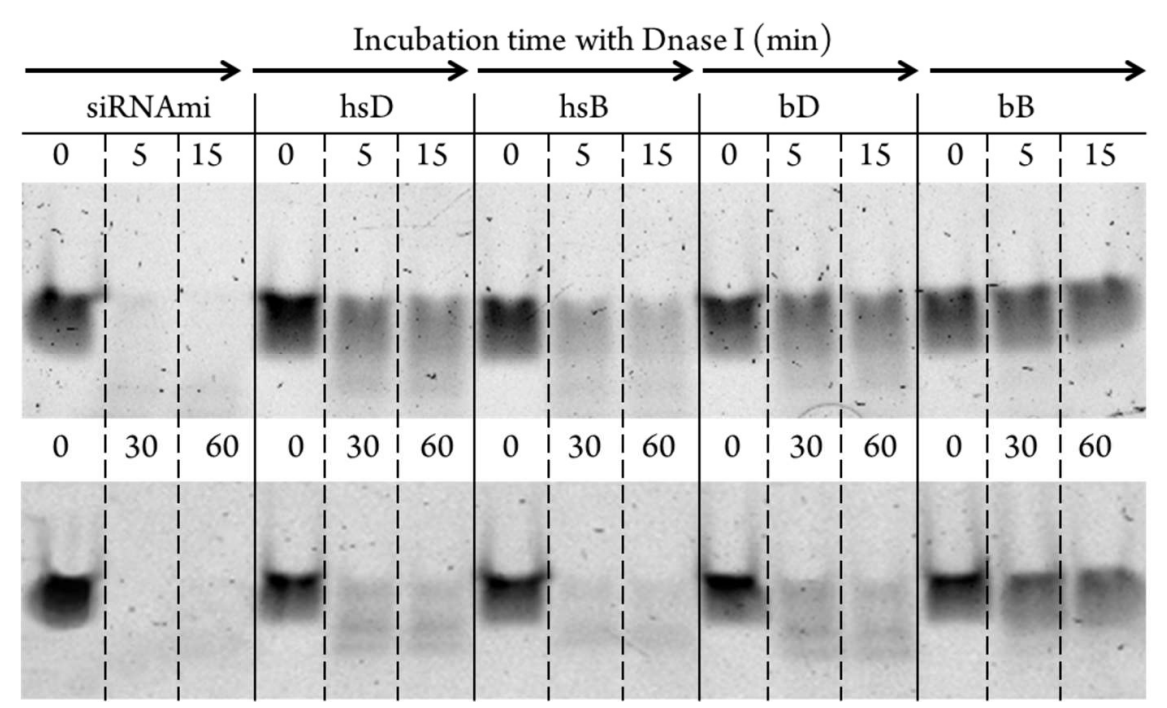

Figure 7. siRNAmi degradation determined by PAGE after $0,5,15,30$ and 60 min of incubation with DNase I. Naked siRNAmi. N/P 160 dendriplexes with: hsD, hsB, bD and bB.

3.4.3. Cellular Association and Uptake. The ability of the dendriplexes from $\mathrm{bD} / \mathrm{bB}$ and $\mathrm{hsD} / \mathrm{hsB}$ to associate and to cross the cell membrane was investigated. U2OS cells stably expressing the fusion protein eGFP-Luciferase (U2OS/eGFPLuc cells) were incubated for $24 \mathrm{~h}$ at $37{ }^{\circ} \mathrm{C}$ with the dendriplexes carrying a siRNAmi labeled with Cy5, a cyanine fluorescence marker. Then, cells were analyzed by flow cytometry, imaging flow cytometry and confocal fluorescence microscopy.

For cells treated with dendriplexes, flow cytometry data (Figure 8a) showed a shift to higher fluorescence intensity (FL) compared with untreated cells (red trace, Figure 8a) as a result of dendriplex cell association/internalization. Higher FL values correlated with an increase in the N/P ratio, what can be explained by a higher NA protection in the dendriplexes. For all vectors, the percentage of positive cells was always above $96 \%$ (Table S1, SI). bB (N/P 80 and 160) showed the highest efficiency of association/internalization with the FL values closer to Lipofectamine ${ }^{\circledR} 2000$ (L2k), a gold standard agent for in vitro transfection (Figure 8a).

The internalization of dendriplexes was further quantified and characterized by imaging flow cytometry, as this technique allows the distinction between nanoparticles only associated to the cell membrane from nanoparticles present in the cell cytoplasm(internalized). The percentage of positive cells was always above $95 \%$ (Table S2, SI), confirming that after $24 \mathrm{~h}$ of contact the dendriplexes were already fully internalized. For all copolymers, the percentage of dendriplex-loaded vesicles (DLVs) per cell (Table S3 and Figure S23, SI) was determined. Cell images were taken in several different planes on the $\mathrm{z}$ axis and an image projection was created. Three groups defining cells with low $(<1.5)$, medium (1.5-5.5) or high (> 5.5) number of DLVs per cell were determined (Figure 8b as well as Table S3 and Figure S23 in SI). It was found that biodegradable copolymers showed higher relative internalization efficiency than their 
hydrolytically stable counterparts. bB was the copolymer with the highest percentage of cells with high number of DLVs (44\%) (Figure 8b and Table S3, SI). Further, confocal microscopy images of U2OS cells reveal a dotted-like Cy5 fluorescence pattern indicative of an endosomal uptake of the dendriplexes (Figure 8c).

The increased NA protection capacity in the bB dendriplexes imparted by the GATGE units and benzyl groups may justify the highest uptake mediated by this system in two ways: i) better siRNA protection means that more of the intact labelled Cy5-siRNA will be able to enter the cell; ii) the extra hydrophobicity imparted by the GATGE can improve cell membrane interactions and assist in internalization.

a)
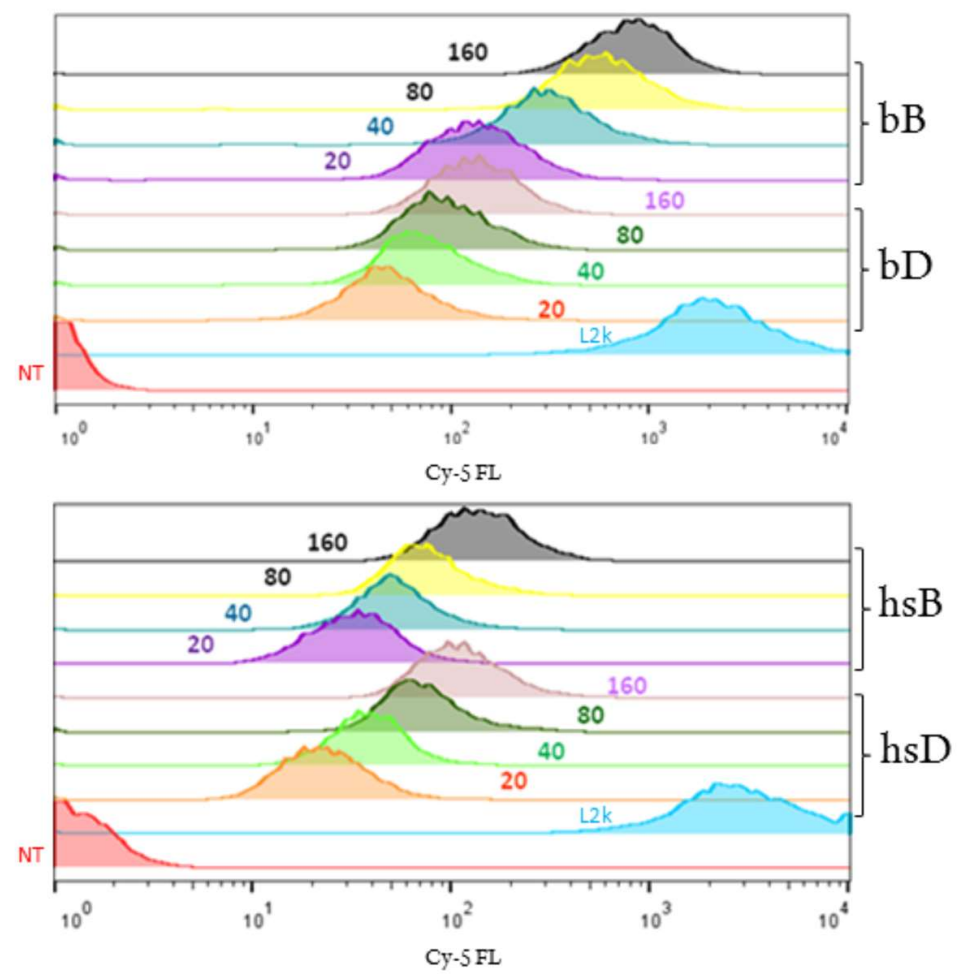

c)

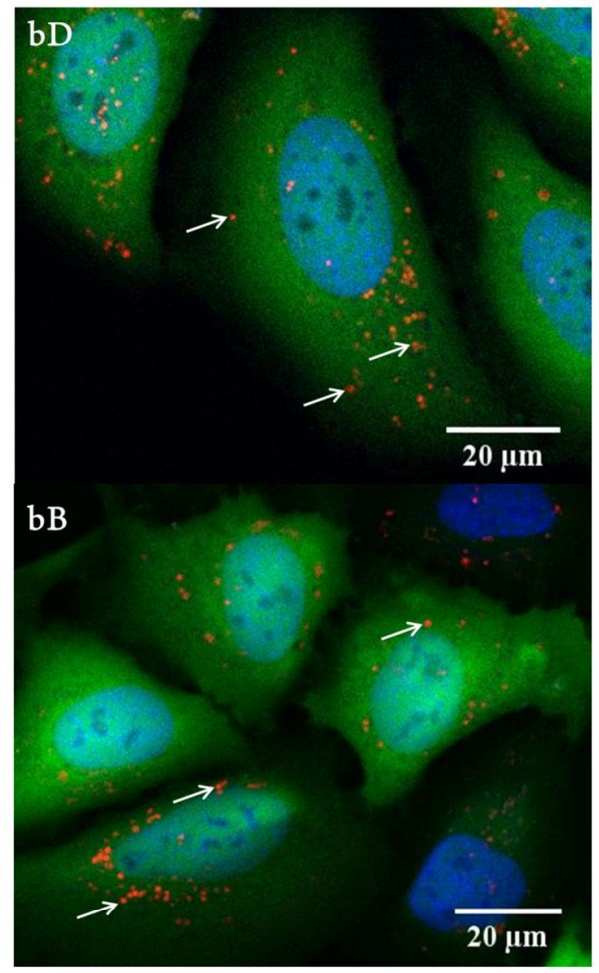

b)
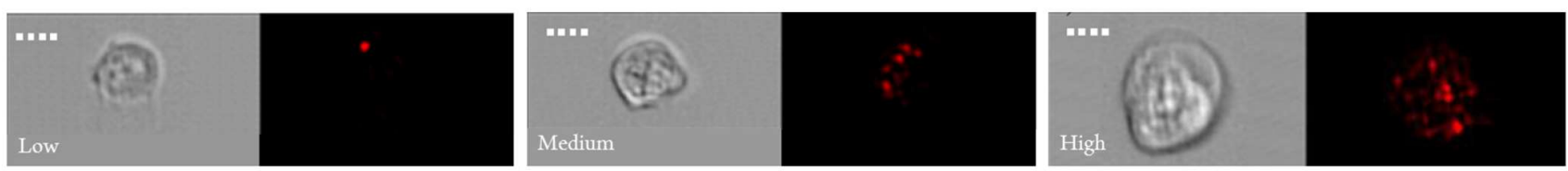

Figure 8. Cellular association of dendriplexes. Dendriplexes containing Cy5 labeled siRNAmi (Cy5siRNAmi) were incubated for $24 \mathrm{~h}$ with U2OS cells at a final siRNAmi concentration of $0.1 \mu \mathrm{M}$. Lipofectamine ${ }^{\circledR} 2000$ (L2k) was used as a control according to manufacturer instructions. a) Flow cytometry characterization at different N/Ps. Highlighted area corresponds to populations of cells with high relative FL. b) Extended Depth of Field images acquired by imaging flow cytometry for Cy5siRNAmi bB dendriplexes at N/P160 (red). Gray background: bright field images; Black background: channel 5 images (Cy-5). Scale bar: $10 \mu \mathrm{m}$. Representative images for every category are shown: Low spot count, Medium Spot Count, and High spot count. c) Confocal microscopy images for bD and bB at N/P 160. Nuclei stained with Hoechst 33342 (in blue). Cells expressing eGFPLuc (in green). Cy5siRNAmi dendriplexes (in red). 
3.4.4. Transfection Efficiency. The ability of the dendriplexes to mediate gene silencing was tested in U2OS/eGFPLuc cells. Cells were incubated for $24 \mathrm{~h}$ at $37^{\circ} \mathrm{C}$ with dendriplexes containing an anti-eGFP siRNA (Figures 9a and 9c) and with dendriplexes complexing a non-coding siRNA (negative control, Figure 9b). Transfection efficiency was assessed by measuring the decrease of luciferase activity relative to non-treated cells. When cells were treated with bD dendriplex complexing the non-coding siRNA (N/P 160) an increase in luciferase activity was observed (Figure 9b), an effect that can be ascribed to influences of the vector on promoter activity. ${ }^{59,60}$ Experiments performed with anti-eGFP siRNA dendriplexes based on $\mathrm{bD}$ at several N/P afforded a small decrease in luciferase activity (Figure 9a), in agreement with previous reports from other groups. ${ }^{22,61}$ To explore if these results pointed to an impairment of the endosomal escape, a critical challenge in siRNA delivery - chloroquine (CQ), a disruptor of endosomal vesicles, was added during the transfection period. Under the applied conditions, CQ will induce the accumulation of counter ions in the endosomes, resulting in endosomal swelling and rupture. ${ }^{62,63}$ In the presence of CQ, a significant decrease in luciferase activity was observed at $\mathrm{N} / \mathrm{P} \geq 40$, which accounts at $\mathrm{N} / \mathrm{P} 160$ for a silencing up to $80 \%$. When the transfection efficiency for all dendritic carriers at a constant $\mathrm{N} / \mathrm{P}$ was tested in the presence of this agent, silencing was observed in all cases, except for the hydrolytically stable hsB copolymer (Figure 9c); being the highest transfection efficiencies mediated by the biodegradable series ( $\mathrm{bD}$ and $\mathrm{bB}$ ). This functional effect can be associated with the degradability of the GATGE building unit, having esters linkages as degradation points close to the siRNA binding sites. Consequently, degradability is revealed to be an important feature for siRNA release from these particles, contributing to the improvement of the transfection efficiency relative to the hydrolytically stable PEGGATG counterparts.
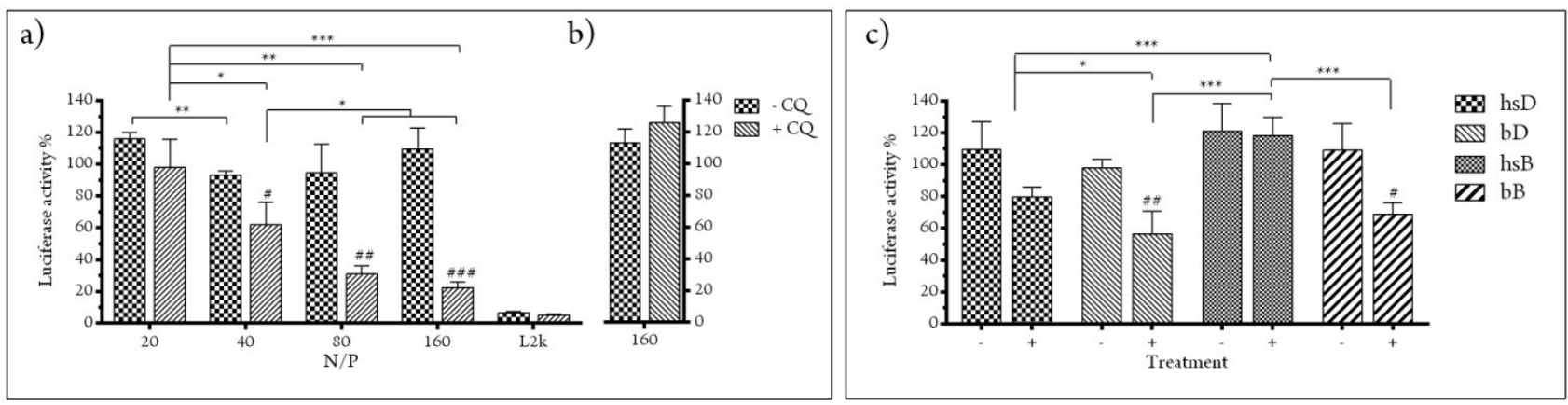

Figure 9. Percentage of Luciferase activity upon $72 \mathrm{~h}$ post-transfection for: (a) anti-eGFP siRNA/bD dendriplexes at different N/P, and L2k. (b) non-coding siRNA/bD dendriplex at N/P 160. Experiments in the absence (-) and presence (+) of CQ. (c) Hydrolytically stable and biodegradable anti-eGFP siRNA/PEG-GATG dendriplexes: hsD, bD, hsB, bAr at N/P 160. (Experiments in the absence (-) and presence $(+)$ of CQ). One-way ANOVA tests were used for statistical analysis. Significant differences: ${ }^{*} p$ $<0.05,{ }^{*} \mathrm{p}<0.01$ and ${ }^{* * *} \mathrm{p}<0.001$. For each N/P, the symbol \# indicates significant differences between experiments in the absence and presence of CQ. 
As the dendriplexes show good potential as nucleic acid carriers when in the presence of CQ, future studies will be conducted aiming to intrinsically capacitate the dendriplexes with these endosomolytic properties as we had previously explored. ${ }^{64}$

\section{CONCLUSION}

We have reported new hybrid-biodegradable, biocompatible, non-toxic, and water-soluble azideterminated PEG-GATGE dendritic block copolymers. The novel GATGE building unit incorporates a gallic acid core and degradable triethylene glycol butanoate arms. Their successful CuAAC functionalization with alkynated and unprotected amine groups allowed the efficient complexation and protection of siRNA and, therefore, to explore their potential as vectors of this nucleic acid. The hydrophobic character of the GATGE unit confers to these hydrolyzable systems a great ability to complex, protect and mediate the internalization of siRNA. Moreover, the localization of the degradation points at the dendritic shell was important for a better siRNA release from the dendriplexes, contributing to a significant improvement of the transfection efficiency compared to their hydrolytically stable PEGGATG counterparts. The biodegradable GATGE dendritic architectures developed in this work have a great potential in the biomedical field. The presence of peripheral azides on their surface will allow an efficient and easy decoration by means of $\mathrm{CuAAC}$ with alternative functional groups and ligands. Therefore, they will be able to act as suitable vectors not only for nucleic acid delivery, but also for broader applications in drug delivery, diagnosis, vaccines, tissue engineering, among others, finally leading to new strategies for nanomedicine.

Supplementary Information. Supporting data to this article can be found online at the publications website. This material includes ${ }^{1} \mathrm{H}$ and ${ }^{13} \mathrm{C}$ NMR, MALDI-TOF and FTIR spectra of all corresponding new compounds synthesized, degradability studies, as well as dendriplex characterization and internalization data.

\section{Acknowledgment}

The authors would like to acknowledge the FEDER funds through the Programa Operacional Factores de Competitividade - COMPETE and the Portuguese funds through FCT - Fundação para a Ciência e a Tecnologia (PTDC/CTM-NAN/112428/2009 and PTDC/CTM-NAN/3547/2014) that supported this work and the FCT / MEC through National Funds and, when applicable, co-financed by the FEDER via the PT2020 Partnership Agreement under the 4293 Unit I\&D. V. Leiro acknowledges the support by FCT 
(SFRH/BPD/69110/2010) and by the project NORTE-01-0145-FEDER-000012, financed by Norte Portugal Regional Operational Programme (NORTE 2020), under the PORTUGAL 2020 Partnership Agreement, through the European Regional Development Fund (ERDF). P.M.D. Moreno acknowledges the support from the Marie Curie Actions of the European Community's Seventh Framework Program (PIEF-GA-2011-300485) and FCT fellowship (SFRH/BPD/108738/2015). This work was also financially supported by the Spanish Government (MINECO: CTQ2012-34790, CTQ2012-33436) and the Xunta de Galicia (CN2011/037). Authors acknowledge Dr. Maria G Lázaro from the Bioimaging Center for Biomaterials and Regenerative Therapies (b.IMAGE) for her help with Imaging Flow Cytometry and the Centro de Materiais da Universidade do Porto (CEMUP) for NMR and MS analysis.

\section{REFERENCES}

1. S. Svenson and D. Tomalia, Adv Drug Deliver Rev, 2005, 57, 2106-2129.

2. O. Rolland, C. O. Turrin, A. M. Caminade and J. P. Majoral, New J. Chem., 2009, 33, 1809-1824.

3. S. H. Medina and M. E. El-Sayed, Chem. Rev., 2009, 109, 3141-3157.

4. R. K. Tekade, P. V. Kumar and N. K. Jain, Chem. Rev., 2009, 109, 49-87.

5. M. A. Mintzer and M. W. Grinstaff, Chem. Soc. Rev., 2011, 40, 173-190.

6. C. Dufes, I. Uchegbu and A. Schatzlein, Adv Drug Deliver Rev, 2005, 57, 2177-2202.

7. M. A. Mintzer and E. E. Simanek, Chemical Reviews, 2009, 109, 259-302.

8. $\quad$ D. Castanotto and J. J. Rossi, Nature, 2009, 457, 426-433.

9. J. L. Santos, H. Oliveira, D. Pandita, J. Rodrigues, A. P. Pêgo, P. L. Granja and H. Tomás, Journal of Controlled Release, 2010, 144, 55-64.

10. S. Biswas and V. P. Torchilin, Pharmaceuticals, 2013, 6, 161-183.

11. M. Mannisto, S. Vanderkerken, V. Toncheva, M. Elomaa, M. Ruponen, E. Schacht and A. Urtti, Journal of controlled release : official journal of the Controlled Release Society, 2002, 83, 169-182.

12. T. Merdan, K. Kunath, H. Petersen, U. Bakowsky, K. H. Voigt, J. Kopecek and T. Kissel, Bioconjugate Chemistry, 2005, 16, 785-792.

13. L. E. van Vlerken, T. K. Vyas and M. M. Amiji, Pharm Res-Dordr, 2007, 24, 1405-1414.

14. S. Thakur, P. Kesharwani, R. K. Tekade and N. K. Jain, Polymer, 2015, 59, 67-92.

15. A. Sousa-Herves, R. Riguera and E. Fernandez-Megia, New J. Chem., 2012, 36, 205-210.

16. D. Luo, K. Haverstick, N. Belcheva, E. Han and W. M. Saltzman, Macromolecules, 2002, 35, $3456-3462$.

17. T.-i. Kim, H. J. Seo, J. S. Choi, H.-S. Jang, J.-u. Baek, K. Kim and J.-S. Park, Biomacromolecules, $2004,5,2487-$ 2492.

18. K. C. Wood, S. R. Little, R. Langer and P. T. Hammond, Angewandte Chemie, International Edition, 2005, 44, 67046708.

19. T.-i. Kim, J.-u. Baek, J. K. Yoon, J. S. Choi, K. Kim and J.-s. Park, Bioconjugate Chemistry, 2007, 18, $309-317$.

20. M. Raviña, M. de la Fuente, J. Correa, A. Sousa-Herves, J. Pinto, E. Fernandez-Megia, R. Riguera, A. Sanchez and M. J. Alonso, Macromolecules, 2010, 43, 6953-6961.

21. M. de la Fuente, M. Raviña, A. Sousa-Herves, J. Correa, R. Riguera, E. Fernandez-Megia, A. Sánchez and M. J. Alonso, Nanomedicine, 2012, 7, 1667-1681.

22. J. Reyes-Reveles, R. Sedaghat-Herati, D. R. Gilley, A. M. Schaeffer, K. C. Ghosh, T. D. Greene, H. E. Gann, W. A. Dowler, S. Kramer, J. M. Dean and R. K. Delong, Biomacromolecules, 2013, 14, 4108-4115.

23. R. F. Barth, D. M. Adams, A. H. Soloway, F. Alam and M. W. Darby, Bioconjugate Chemistry, 1994, 5, 58-66.

24. N. Malik, E. Evagorou and R. Duncan, Anticancer Drugs, 1999, 10, 767-776.

25. N. Malik, R. Wiwattanapatapee, R. Klopsch, K. Lorenz, H. Frey, J. W. Weener, E. W. Meijer, W. Paulus and R. Duncan, Journal of Controlled Release, 2000, 65, 133-148.

26. K. Jain, P. Kesharwani, U. Gupta and N. K. Jain, International Journal of Pharmaceutics, 2010, 394, $122-142$.

27. V. Leiro, J. P. Garcia, H. Tomas and A. P. Pego, Bioconjugate Chemistry, 2015, 26, 1182-1197.

28. J. H. S. Kuo and Y. L. Lin, J Biotechnol, 2007, 129, 383-390.

29. M. Labieniec, O. Ulicna, O. Vancova, R. Glowacki, K. Sebekova, E. Bald, T. Gabryelak and C. Watala, International Journal of Pharmaceutics, 2008, 364, 142-149.

30. C. Li, H. Liu, Y. Sun, H. Wang, F. Guo, S. Rao, J. Deng, Y. Zhang, Y. Miao, C. Guo, J. Meng, X. Chen, L. Li, D. Li, H. Xu, H. Wang, B. Li and C. Jiang, Journal of Molecular Cell Biology, 2009, 1, 37-45.

31. J. H. S. Kuo, M. J. Liou and H. C. Chiu, Molecular Pharmaceutics, 2010, 7, 805-814. 

Brooks, H. Ghandehari and D. W. Grainger, ACS Nano, 2012, 6, 9900-9910.

33. M. S. Shim and Y. J. Kwon, Biomaterials, 2010, 31, 3404-3413.

34. C. L. He, X. L. Zhuang, Z. H. Tang, H. Y. Tian and X. S. Chen, Adv Healthc Mater, 2012, 1, 48-78.

35. S. J. Guillaudeu, M. E. Fox, Y. M. Haidar, E. E. Dy, F. C. Szoka and J. M. J. Fréchet, Bioconjugate chemistry, 2008, 19, 461-469.

36. D. G. van der Poll, H. M. Kieler-Ferguson, W. C. Floyd, S. J. Guillaudeu, K. Jerger, F. C. Szoka and J. M. Fréchet, Bioconjugate Chemistry, 2010, 21, 764-773.

37. A. Barnard, P. Posocco, S. Pricl, M. Calderon, R. Haag, M. E. Hwang, V. W. Shum, D. W. Pack and D. K. Smith, J Am Chem Soc, 2011, 133, 20288-20300.

38. D. J. Welsh, S. P. Jones and D. K. Smith, Angewandte Chemie, International Edition, 2009, 48, 4047-4051.

39. A. Barnard, M. Calderon, A. Tschiche, R. Haag and D. K. Smith, Organic \& biomolecular chemistry, 2012, 10, 84038409.

40. A. Barnard, P. Posocco, M. Fermeglia, A. Tschiche, M. Calderon, S. Pricl and D. K. Smith, Organic \& biomolecular chemistry, 2014, 12, 446-455.

41. J. Movellan, R. Gonzalez-Pastor, P. Martin-Duque, T. Sierra, J. M. de la Fuente and J. L. Serrano, Macromol. Biosci., 2015, 15, 657-667.

42. A. Sousa-Herves, R. Novoa-Carballal, R. Riguera and E. Fernandez-Megia, The AAPS journal, 2014 , 16, 948-961.

43. C. W. Tornoe, C. Christensen and M. Meldal, J Org Chem, 2002, 67, 3057-3064.

44. V. V. Rostovtsev, L. G. Green, V. V. Fokin and K. B. Sharpless, Angew Chem Int Ed Engl, 2002, 41, $2596-2599$.

45. E. Lallana, F. Fernandez-Trillo, A. Sousa-Herves, R. Riguera and E. Fernandez-Megia, Pharm. Res., 2012, 29, 902921.

46. A. Sousa-Herves, C. Sanchez Espinel, A. Fahmi, A. Gonzalez-Fernandez and E. Fernandez-Megia, Nanoscale, 2015, 7, 3933-3940.

47. $\quad$ S. P. Amaral, M. Fernandez-Villamarin, J. Correa, R. Riguera and E. Fernandez-Megia, Org Lett, 2011, 13, 45224525.

48. E. Fernandez-Megia, J. Correa and R. Riguera, Biomacromolecules, 2006, 7, 3104-3111.

49. B. H. Zinselmeyer, S. P. Mackay, A. G. Schatzlein and I. F. Uchegbu, Pharm Res, 2002, 19, 960-967.

50. S. Hurrell, G. E. Milroy and R. E. Cameron, Polymer, 2003, 44, 1421-1424.

51. D. J. Gary, N. Puri and Y. Y. Won, Journal of Controlled Release, 2007, 121, 64-73.

52. M. A. Mintzer, O. M. Merkel, T. Kissel and E. E. Simanek, New J Chem, 2009, 33, 1918-1925.

53. O. M. Merkel, M. A. Mintzer, J. Sitterberg, U. Bakowsky, E. E. Simanek and T. Kissel, Bioconjug Chem, 2009, 20, 1799-1806.

54. O. M. Merkel, M. A. Mintzer, D. Librizzi, O. Samsonova, T. Dicke, B. Sproat, H. Garn, P. J. Barth, E. E. Simanek and T. Kissel, Mol Pharm, 2010, 7, 969-983.

55. A. Sousa-Herves, E. Fernandez-Megia and R. Riguera, Chem Commun (Camb), 2008, DOI: 10.1039/b805208e, 31363138 .

56. M. Fernandez-Villamarin, A. Sousa-Herves, S. Porto, N. Guldris, J. Martinez-Costas, R. Riguera and E. FernandezMegia, Unpublished results.

57. A. Akin and B. Giuseppe, Cold Spring Harbor perspectives in biology, 2013, 5.

58. O. M. Merkel, M. Zheng, M. A. Mintzer, G. M. Pavan, D. Librizzi, M. Maly, H. Hoffken, A. Danani, E. E. Simanek and T. Kissel, Journal of controlled release : official journal of the Controlled Release Society, 2011, 153, 23-33.

59. A. Beyerle, M. Irmler, J. Beckers, T. Kissel and T. Stoeger, Mol Pharm, 2010, 7, 727-737.

60. O. M. Merkel, A. Beyerle, B. M. Beckmann, M. Zheng, R. K. Hartmann, T. Stoger and T. H. Kissel, Biomaterials, 2011, 32, 2388-2398.

61. L. P. Mahesh, Z. Min, T. Oleh, B. G. Olga, H. Huixin and M. Tamara, Biomacromolecules, 2009, 10, $258-266$.

62. P. Erbacher, A. C. Roche, M. Monsigny and P. Midoux, Exp Cell Res, 1996, 225, 186-194.

63. K. Ciftci and R. J. Levy, Int J Pharm, 2001, 218, 81-92.

64. C. Moreira, H. Oliveira, L. R. Pires, S. Simoes, M. A. Barbosa and A. P. Pego, Acta biomaterialia, 2009, 5, 29953006. 